\title{
Short term optical defocus perturbs normal developmental shifts in retina/RPE protein abundance
}

\author{
Nina Riddell ${ }^{{ }^{*}}$ (D) Pierre Faou ${ }^{2}$ and Sheila G. Crewther ${ }^{1}$
}

\begin{abstract}
Background: Myopia (short-sightedness) affects approximately 1.4 billion people worldwide, and prevalence is increasing. Animal models induced by defocusing lenses show striking similarity with human myopia in terms of morphology and the implicated genetic pathways. Less is known about proteome changes in animals. Thus, the present study aimed to improve understanding of protein pathway responses to lens defocus, with an emphasis on relating expression changes to no lens control development and identifying bidirectional and/or distinct pathways across myopia and hyperopia (long-sightedness) models.

Results: Quantitative label-free proteomics and gene set enrichment analysis (GSEA) were used to examine protein pathway expression in the retina/RPE of chicks following $6 \mathrm{~h}$ and $48 \mathrm{~h}$ of myopia induction with -10 dioptre (D) lenses, hyperopia induction with $+10 \mathrm{D}$ lenses, or normal no lens rearing. Seventy-one pathways linked to cell development and neuronal maturation were differentially enriched between 6 and $48 \mathrm{~h}$ in no lens chicks. The majority of these normal developmental changes were disrupted by lens-wear (47 of 71 pathways), however, only 11 pathways displayed distinct expression profiles across the lens conditions. Most notably, negative lens-wear induced up-regulation of proteins involved in ATP-driven ion transport, calcium homeostasis, and GABA signalling between 6 and 48 h, while the same proteins were down-regulated over time in normally developing chicks. Glutamate and bicarbonate/chloride transporters were also down-regulated over time in normally developing chicks, and positive lens-wear inhibited this down-regulation.

Conclusions: The chick retina/RPE proteome undergoes extensive pathway expression shifts during normal development. Most of these pathways are further disrupted by lens-wear. The identified expression patterns suggest close interactions between neurotransmission (as exemplified by increased GABA receptor and synaptic protein expression), cellular ion homeostasis, and associated energy resources during myopia induction. We have also provided novel evidence for changes to SLC-mediated transmembrane transport during hyperopia induction, with potential implications for signalling at the photoreceptor-bipolar synapse. These findings reflect a key role for perturbed neurotransmission and ionic homeostasis in optically-induced refractive errors, and are predicted by our Retinal Ion Driven Efflux (RIDE) model.
\end{abstract}

Keywords: Myopia, Hyperopia, Chick, Proteomics, Mass spectrometry, Development, Emmetropization, Neurotransmission

\footnotetext{
* Correspondence: N.Riddell@latrobe.edu.au

${ }^{1}$ Department of Psychology and Counselling, School of Psychology and

Public Health, La Trobe University, Plenty Rd., Bundoora, Melbourne, VIC

3083, Australia

Full list of author information is available at the end of the article
}

(c) The Author(s). 2018 Open Access This article is distributed under the terms of the Creative Commons Attribution 4.0 International License (http://creativecommons.org/licenses/by/4.0/), which permits unrestricted use, distribution, and reproduction in any medium, provided you give appropriate credit to the original author(s) and the source, provide a link to the Creative Commons license, and indicate if changes were made. The Creative Commons Public Domain Dedication waiver (http://creativecommons.org/publicdomain/zero/1.0/) applies to the data made available in this article, unless otherwise stated. 


\section{Background}

The prevalence of myopia (short-sightedness) is increasing worldwide, and by 2050 it is expected that approximately 4.8 billion people will be myopic (almost 1 billion of whom will be highly myopic) [1]. Myopia is also a major risk factor for severe sight threatening pathologies including choroidal neovascularization, retinal detachment, glaucoma, and cataract [2-4]. Such myopia-associated pathologies are often the most frequent cause of blindness in younger age-groups e.g. [5-7], highlighting the urgent need to understand the underlying biological processes so that effective treatments can be developed.

Myopia and hyperopia (long-sightedness) occur when the eye grows too long or short, respectively, for its refractive power $[8,9]$. Such a disruption in the normal emmetropization process (i.e., the active process whereby the predominantly hyperopic eyes of infants increase in size to facilitate image focus on the retina [10-14]) occurs in response to change in the visual environment early in life in all human and animal species studied to date [15-24]. Animals reared with frosted occluders or negative defocusing lenses over one eye rapidly develop axial myopia, while those reared with positive defocusing lenses exhibit slower ocular growth and refractive hyperopia [16, 24]. Myopia in humans and animal models is characterized by reduced visual acuity, axial elongation, thinning of the retina, choroid and fibrous sclera [25-36], and physiological changes in the electroretinogram [37-41]. Chick myopia develops even after optic nerve section, suggesting that ocular growth is regulated by molecular mechanisms that are predominantly local to the eye (and to the retina in particular given that it is the only light sensitive element and the first tissue in which visual processing occurs) [30, 42-46].

Exploratory gene [47-58] and protein [59-69] expression profiling has been used in extensive attempts to elucidate the retinal signalling cascades that regulate ocular growth and refractive compensation in animal models. We have recently demonstrated good concordance between the single genes and proteins implicated in these studies and those linked to myopia and its sequelae (including macular degeneration and choroidal neovascularization) in humans $[56,66,70]$. Pathway-focused analyses have begun to identify unifying themes at the transcriptome level, including increased expression of mitochondrial metabolism and inflammatory (particularly complement/coagulation) pathways in the retina/RPE/ choroid during myopia induction [56-58]. Less is known about pathway expression at the protein level, as most studies to date have used low throughput gel-based methods to identify highly up- and down-regulated proteins [70]. This approach generally provides poor representation of lowly abundant proteins, highly acidic/basic proteins, and hydrophobic proteins [71]. It also precludes the analysis of whole pathways using threshold-free functional class scoring techniques like Gene Set Enrichment Analysis (GSEA). GSEA is based on the assumption that coordinated changes in the expression of genes within a pathway are likely to be biologically important, even if the changes are modest. Unlike over-representation techniques (which have been commonly used in refractive error research e.g. [51, 53, 55, 56, 72]), GSEA analyses the entire dataset without applying a cut-off. Pathway scores are based on the expression of all genes or proteins in the class. Consequently, the results are more stable and the analysis can detect coordinated but subtle changes in the expression of gene sets that are missed by single gene and over-representation analyses [73, 74].

In addition to underutilization of pathway analysis techniques, few retinal proteomic studies have compared multiple ocular growth conditions or multiple time-points $[65,66]$. At the transcriptome level, studies profiling the retina during both myopia and hyperopia induction have identified many similar and distinct gene expression profiles across the two conditions [55-57]. Bidirectional responses appear comparatively rare, except when the analysis is specifically designed to identify such changes (e.g. by identifying pathways correlated with ocular refraction across myopic and hyperopic groups [57]). Studies profiling multiple time-points have demonstrated that different genes are involved in the initiation versus the progression of optically-induced refractive errors e.g. [50, 51, 57], and that some of the genes implicated during refractive error induction are also developmentally regulated (i.e., changing over time in normally developing control retina) [57].

To address the lack of high throughput retinal proteomic studies comparing multiple lenses and time-points, we have recently used LC-ESI-MS/MS to examine single differentially-expressed proteins in the retina/RPE of chicks following $6 \mathrm{~h}$ and $48 \mathrm{~h}$ of myopia induction with $-10 \mathrm{di}-$ optre (D) lenses, hyperopia induction with $+10 \mathrm{D}$ lenses, or normal no lens rearing. We identified a similar pattern of single protein changes to that reported in transcriptome studies [55-57], with significant refractive compensation and $>140$ differentially abundant proteins evident in both lens groups at $6 \mathrm{~h}$ and $48 \mathrm{~h}$. The response to negative and positive lenses was highly similar at both time-points, and only 13 proteins displayed sign-of-defocus dependent changes [66]. Many of the identified proteins had previously been linked to the development of secondary pathologies (macular degeneration and choroidal neovascularization) in humans, and proteins negatively correlated with ocular refraction across lens groups at $6 \mathrm{~h}$ were enriched for genes linked to human photoreceptor dystrophies and mitochondrial disorders [66]. This finding is consistent with human genetic studies showing a high incidence of refractive errors in individuals with inherited photoreceptor dystrophies [75] as well as a recent refractive 
error genome-wide association meta-analyses implicating 'abnormal photoreceptor inner segment morphology' as the most significant gene set [76]. Such changes to photoreceptor dynamics are predicted by Crewther's Retinal Ion-Driven Fluid Efflux (RIDE) model [77].

Our earlier proteomic study [66] emphasized the relevance of the chick retina/RPE lens model to human myopia, and provided support for the early disruption of photoreceptor signalling. However, in this previous study we did not analyse changes over time within each lens condition and as such could not relate protein shifts during lens-wear to any corresponding shifts occurring in the no lens group undergoing normal emmetropization. The $>390$ proteins implicated across 6 and 48 h time-points highlights the need for a pathway-based approach to adequately summarize the biological processes involved in adapting to the rapid refractive compensation and photoreceptor changes occurring during the initial hours of lens-wear. Thus, in the present study we re-analysed our previously published proteomic dataset [66] using a GSEA pathway approach with the aim of (i) improving understanding of the relationship between lens-induced pathway expression changes and normal no lens development, and (ii) identifying bidirectional and/or distinct pathway expression shifts in the two lens groups that may have potential for the development of targeted therapies to inhibit or slow the progression of excessive myopic ocular growth.

\section{Results}

As previously reported, chicks were assigned to a lens condition (negative lens, positive lens, or no lens) on post-hatch day 5 (P5). Experimental eye refraction and axial dimensions were measured following a further $6 \mathrm{~h}$ (P5) and $48 \mathrm{~h}$ (P7) of rearing. These biometric measures (Additional file 1: Table S1) confirmed that chicks in the positive and negative lens conditions displayed compensatory changes in refraction and axial length at the $6 \mathrm{~h}$ time-point, and that refractive compensation was almost complete in both lens conditions by $48 \mathrm{~h}$ (negative lens mean refraction $\pm \mathrm{SE}=-9.70 \mathrm{D} \pm 0.41 \mathrm{D}$, positive lens $=7.70 \mathrm{D} \pm 0.44 \mathrm{D}$ ). Normally developing no lens chicks were approximately emmetropic at both time-points (no lens $6 \mathrm{~h}=0 \mathrm{D} \pm 0.45 \mathrm{D}, 48 \mathrm{~h}=0.63 \mathrm{D} \pm 0.16 \mathrm{D}$ ). Statistical analyses reported in our previous publication [66] confirmed that the refractive state of all lens groups was significantly different at both time points ( $p<0.01$ for all comparisons). After biometric data collection, the retina/RPE was extracted for label-free LC-ESI-MS/MS proteomic analysis. The pre-processed LC-ESI-MS/MS matrix is provided in Additional file 2: Table S2.

The LC-ESI-MS/MS dataset was analysed using GSEA [74] to identify enriched Reactome pathways between lens groups at each time-point, and within each of the three lens groups over time (i.e., between the 6 and $48 \mathrm{~h}$ time-points). Eighty-three of the 431 Reactome pathways measured in the dataset were significantly enriched $(F D R<0.05)$ in one or more of these pairwise comparisons. To simplify the interpretation and remove redundancy from the pathway-level findings, pathways with the same leading edge subset (LES) proteins driving their enrichment were grouped into clusters (see the Methods section for further explanation of the LES). Additional file 3: Figure S1-S2 provides a visual representation of the pathway clustering.

This grouping revealed nine clusters of pathways representing common cellular processes related to nucleocytoplasmic transport, gene expression regulation, translation, mitochondrial protein import, rab GTPases, integration of energy metabolism, ion and vascular homeostasis, signal transduction, and solute transport (Table 1). As outlined in Table 1, pathways from the nucleocytoplasmic transport cluster were up-regulated over time between 6 and $48 \mathrm{~h}$ in normally developing no lens chicks. Pathways from the remaining 8 clusters were down-regulated over time during normal development. Up-regulation of pathways from the nucleocytoplasmic transport cluster was preserved in the positive lens condition; however, positive and negative lens-wear perturbed the timing, strength, and/or direction of all other normal developmental shifts. The following sections present the pairwise enrichment results for each cluster in detail.

\section{Nucleocytoplasmic transport cluster}

Thirty-eight of the 83 implicated pathways were assigned to the 'nucleocytoplasmic transport' cluster on the basis of common LES proteins. The pairwise enrichment profiles for the pathways in this cluster are represented in each row of the Fig. 1a bubble plot; the lens relative to no lens comparisons at 6 and $48 \mathrm{~h}$ are highlighted in grey, and within group changes over time are interposed between them. Statistically significant enrichments $(F D R<0.05)$ are indicated by circle fill, and normalized enrichment scores (NES) are indicated by circle size. The NES is the primary statistic for comparing enrichment results; it represents the degree to which proteins from the pathway were over-represented at the top or bottom of the ranked protein list (after accounting for variations in pathway size). Accordingly, larger circle sizes indicate a greater difference in pathway expression between the two conditions.

As illustrated in Fig. 1a, the 38 pathways in the nucleocytoplasmic transport cluster were up regulated over time between $6 \mathrm{~h}$ and $48 \mathrm{~h}$ in chicks wearing positive lenses and/or no lens. Most of these pathways were related to the nucleocytoplasmic transport of RNA and proteins (including ribosomal proteins), with LES comprised primarily of nuclear pore complex subunits (NUP62, NUP153, NUP37, NUP155, NUP35; Fig. 1b). Two heat shock pathways were also implicated ('regulation of HSF1-mediated heat shock response' and 'cellular response to heat stress'; Fig. 1a), with LES comprised of nuclear pore complex 
Table 1 Summary of pathway enrichment within each cluster

\begin{tabular}{|c|c|c|}
\hline Cluster name & Pathways in cluster & Significant $(F D R<0.05)$ pathway expression changes \\
\hline \multirow[t]{3}{*}{ Nucleocytoplasmic transport } & \multirow[t]{3}{*}{38} & 24 pathways up over time in no lens \& positive lens \\
\hline & & 8 pathways up over time in no lens \\
\hline & & 6 pathways up over time in positive lens \\
\hline \multirow[t]{3}{*}{ Regulation of gene expression } & \multirow[t]{3}{*}{8} & 1 pathway down in negative $\&$ positive vs. no lens at $6 \mathrm{~h}, \&$ down over time in no lens \\
\hline & & 6 pathways down in positive vs. no lens at $6 \mathrm{~h}, \&$ down over time in no lens \\
\hline & & 1 pathway down in negative vs. no lens at $48 \mathrm{~h}$ \\
\hline Translation & 22 & 22 pathways down over time in no lens \\
\hline Mitochondrial import & 1 & 1 pathway down over time in no lens \\
\hline rab GTPase & 1 & 1 pathway down over time in no lens \\
\hline Integration of energy metabolism & 2 & 2 pathways down over time in no lens \\
\hline \multirow[t]{3}{*}{ Ion and vascular homeostasis } & \multirow[t]{3}{*}{6} & 3 pathways up over time in negative lens, \& down over time in no lens \\
\hline & & 1 pathway down in negative vs. positive lens at $6 \mathrm{~h} \& 48 \mathrm{~h}$ \\
\hline & & 2 pathways down in negative vs. positive lens at $6 \mathrm{~h}$ \\
\hline \multirow[t]{2}{*}{ Signal transduction } & \multirow[t]{2}{*}{3} & 1 pathway up over time in negative lens \\
\hline & & 2 pathways down over time in no lens \\
\hline \multirow[t]{2}{*}{ Solute transport } & \multirow[t]{2}{*}{2} & 1 pathway down over time in no lens \\
\hline & & 1 pathway up in positive vs. no lens at $48 \mathrm{~h}$ \\
\hline
\end{tabular}

subunits and proteins linked to heat stress and DNA damage (including CRYAB, HSPA2, HSPH1, RPA1, RPA2, RPA3, and ST13; Fig. 1b).

\section{Regulation of gene expression cluster}

Eight of the 83 implicated pathways were assigned to the 'regulation of gene expression' cluster. Pathways in this cluster were down-regulated between the $6 \mathrm{~h}$ and $48 \mathrm{~h}$ time-points in normally developing chicks, with statistically significant down-regulation occurring for the cellular senescence pathway (consistent with the expected slowing of growth and developmental processes in the no lens group [78]; Fig. 2a). The LES contributing this significant down-regulation (shown in Fig. 2b) was primarily composed of histone proteins from the $\mathrm{H} 2 \mathrm{~A}$, $\mathrm{H} 2 \mathrm{~B}$, and $\mathrm{H} 3$ families (HIST1H2BK, HIST2H2AC, HIST2H3D, and H2AFZ) that form the nucleosome and the $\mathrm{H} 1$ family (HIST1H1C) that promotes higher order chromatin structures. Positive and negative lens-wear induced an earlier and stronger down-regulation of these histone proteins, such that pathways from the cluster were significantly down-regulated in the negative and/or positive lens groups relative to the no lens group at $6 \mathrm{~h}$ (Fig. 2a). One pathway from the cluster, amyloid fiber formation, was down regulated in the negative lens condition relative to no lens condition after $48 \mathrm{~h}$ of lens-wear on P7 (Fig. 2a). This latter pathway's LES was composed of plasma-related proteins FGA, APOA1, and APOA4 as well as histone proteins (HIST1H2BK, HIST2H2AC, and H2AFZ; Fig. 2b).

\section{Translation cluster}

Twenty-two of the 83 implicated pathways were assigned to the 'translation' cluster (Fig. 3a). The LES of these pathways was comprised of proteins involved in ribosomal translation, including 40s and 60s ribosomal subunits (RPS7, RPS10, RPS11, RPS15A, RPS13, RPS2, RPS8, RPS14, RPS3A, RPS28, RPS20, RPL38, RPL27A, RPL23, RPL22, RPL23A, RPL30, RPL12) and eukaryotic translation initiation and elongation factors (EEF1A1, EEF1E1, EIF3M, EIF2S1; Fig. 3b). These translation-related proteins were highly expressed in the retina/RPE of no lens chicks at the $6 \mathrm{~h}$ time-point, and were then significantly down-regulated over time between 6 and 48 h (Fig. 3a-b). Similar to the 'regulation of gene expression cluster', positive and negative lens-wear appeared to bring forward the timing of pathway down-regulation; all pathways in the cluster were non-significantly down regulated in the positive and negative lens conditions relative to the no lens condition at the $6 \mathrm{~h}$ time-point, and non-significantly down regulated over time between 6 and $48 \mathrm{~h}$ in both lens conditions. Consequently, both lens conditions displayed similar expression levels as the no lens animals at the $48 \mathrm{~h}$ time-point (Fig. 3a-b).

\section{Mitochondrial import, Rab GTPase, and integration of energy metabolism clusters}

Proteins from mitochondrial protein import, rab geraylgeranylation, integration of energy metabolism, and regulation of insulin secretion pathways were also highly expressed in the retina/RPE of no lens chicks at $6 \mathrm{~h}$, and then down-regulated over time (Fig. 4a-d). The LES of 
a

Nucleocytoplasmic transport $\frac{0}{2}$ ह

(1) Sumoylation of chromatin
organization proteins 00000000

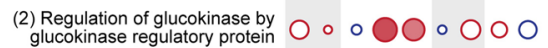

(3) VPR-mediated nuclear import of pics $\mathrm{O} \circ \mathrm{O} 0 \circ \mathrm{O} \mathrm{O}$

(4) Nuclear import of REV protein $\mathrm{O} \circ \mathrm{OO} \circ \mathrm{O} 0 \mathrm{O}$

(5) Regulation of HSF1-mediated

heat shock response $\mathrm{O} \circ 0 \mathrm{O} \circ 000$

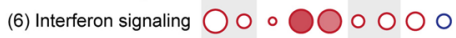

(7) Transport of ribonucleoproteins
into the host nucleus

(8) Non-coding RNA metabolism $000 \mathrm{O} \circ \mathrm{O} \bigcirc$

(9) Interactions of VPR with
host cellular proteins $\circ \circ \bigcirc \bigcirc \circ \bigcirc \bigcirc \bigcirc$

(10) Sumoylation of RNA binding proteins 000000000

(11) Transport of mature mRNA derived 000000000

(12) Sumoylation of DNA $\mathrm{O}$ replication proteins $\circ 0 \bigcirc 00000$

(13) Nuclear envelope breakdown $\mathrm{O} \circ \mathrm{O} 0000$ (14) SNRNP assembly 000000000

(15) Cellular response to heat stress $0 \circ \circ \bigcirc \bigcirc \circ \circ \bigcirc \bigcirc$ (16) Nuclear pore complex disassembly $\mathrm{O} \circ \circ \bigcirc \bigcirc \circ 000$

(17) ISG15 antiviral mechanism $\bigcirc 0 \circ 000000$

(18) Sumo E3 ligases sumoylate $\mathrm{O}$ target proteins $\mathrm{O} \bigcirc \mathrm{O} \circ \mathrm{O} \mathrm{O}$

(19) Export of viral ribonucleoproteins $\mathrm{O}$.

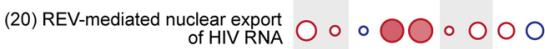

(21) Transport of mature mRNAs derived
from intronless transcripts ○ $\bigcirc \bigcirc \bigcirc \circ \bigcirc \bigcirc \bigcirc$

22) NEP NS2 interacts with the
cellular export machinery

(23) Sumoylation of DNA damage
response and repair proteins $\circ 0000000$

response and repair proteins 000

(24) tRNA processing $0 \circ 000000$

(25) Interactions of REV
with host cellular proteins

(26) Transport of the SLBP independent
mature mRNA ○ $0 \bigcirc \bigcirc \circ 0 \bigcirc \bigcirc$

(27) Antiviral mechanism by
IFN-stimulated genes $\circ \circ \bigcirc \bigcirc \circ 000$

(28) Viral messenger RNA synthesis $\bigcirc \circ \circ \bigcirc \bigcirc \circ 000$

(29) Glucose transport $0 \circ 0 \bigcirc 0 \circ 000$

(30) Hexose uptake $0 \circ 0 \bigcirc 0 \circ 0 \circ 0$

(31) Sumoylation $0 \circ 0 \bigcirc 0 \circ 000$

(32) NS1 mediated effects

on host pathways $\mathrm{O} \circ \mathrm{O} \bigcirc \circ 00$

(33) Host interactions with influenza factors $\bigcirc \circ \circ \bigcirc \bigcirc \circ 000$

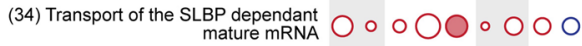

(35) Signaling by FGFR2 $\mathrm{O} \circ \mathrm{O} \bigcirc \mathrm{O} \circ \mathrm{O}$

(36) Signaling by FGFR $O 0 \circ 0000 \circ 0$

(37) tRNA processing in the nucleus $0 \circ 0000000$

(38) Late phase of HIV life cycle $\bigcirc \circ 0 \bigcirc \circ \circ \circ \circ$ b

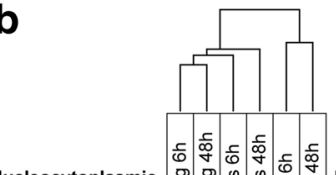

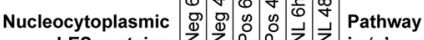

LES proteins

NUP62 / P37198

NUP153 / P49790

NUP37 / Q8NFH4

NUP155 / O75694

RAE1 / P78406

NUP35 / Q8NFH5

HSPA2 / P54652

RPA2 / P15927

ST13 / P50502

RPA3 / P35244

CAMK2G / Q13555

EIF4G3/ O43432

EIF4A2 / Q14240

NCBP1 / Q09161

SNRPF / P62306

WDR77 / Q9BQA1

SNRPE / P62304

PCNA/P12004

CRYAB / P02511

EPRS / P07814

RPA1 / P27694

HSPA4L / 095757

TPR / P12270

NUP43 / Q8NFH3

HSPH1 / Q92598

KPNB1 / Q14974

KPNA5 / 015131

UBE2I / P63279

RANGAP1 / P46060

PRKCA / P17252

PTGES3 / Q15185

RAD21 / 060216

POLR2C / P19387

TIA1 / P31483

PTBP1 / P26599

GTF2B / Q00403

NEDD4L / Q96PU5

SUPT5H / 000267
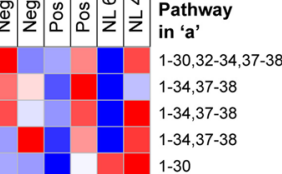

-

$1-30$

1-33

5,15

5,15

5,15

5,15

6,15

$6,17,27$

(17,27

$0,17,27$

$1,14,21,26,34-36,38$

$8,11,14,21$
8,14
8,14

- 8,14
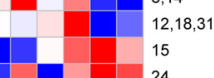

$12,18,31$

4

$5,15,18,23,31$

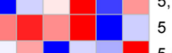

$5-6,12,17-18,27,31-33$

5,15

$6,17,27,32-33$

$6,17,27,32-33$
$6,17,27,32-33$

$10,12,18,23,31$

$12,18,20,25,31,38$

13

15
$18,23,3$

28, $35-36,38$

35-36

35-36

$35-36$

38

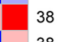

$5-6,10,12-13,15,17-18,23,27-28,31-33$

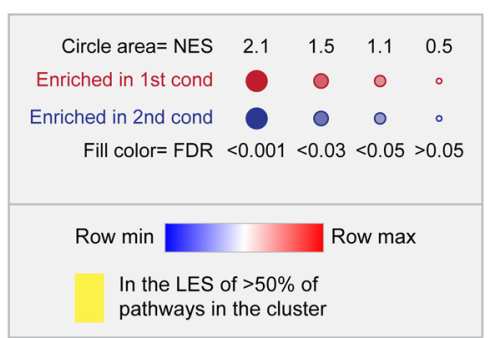

Fig. 1 Pathway enrichment in the nucleocytoplasmic transport cluster. a Bubble plot illustrating the normalized enrichment score (NES) and false discovery rate (FDR) across all pairwise comparisons for the thirty-eight enriched pathways in the 'nucleocytoplasmic transport' cluster. Statistically significant enrichments (FDR < 0.05) are shown as filled circles. $\mathbf{b}$ Heat map showing the mean label-free quantification (LFQ) intensity across lens conditions for all leading edge subset (LES) proteins contributing to the enrichment of one or more nucleocytoplasmic pathways. Note that the LES varied across pathways that were significantly enriched over time in both positive and no lens conditions. Full details of the LES for each comparison are provided in, Additional file 4 Figure $\$ 3$

the mitochondrial protein import pathway was comprised of SLC25A13, which is involved in the calcium-dependent exchange of cytoplasmic glutamate with mitochondrial aspartate, SLC25A4, which is involved in translocation of ADP from the cytoplasm into the mitochondria and ATP from the mitochondria into the cytoplasm, and TIMM9 which participates in the import and insertion of proteins into the mitochondrial inner membrane (Fig. 4b). The LES of the rab geranylgeranylation pathway was comprised of rab GTPases involved in intracellular membrane traffic, including several linked to insulin and glucose signalling (Rab5b, 


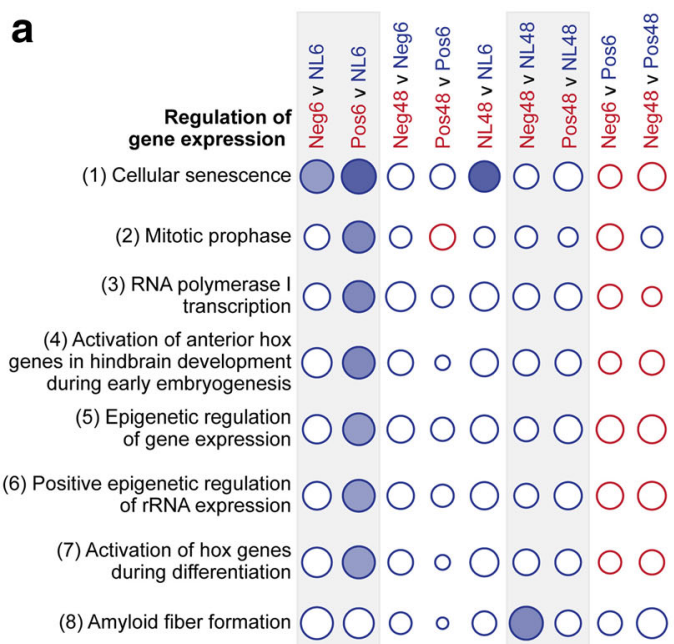

b

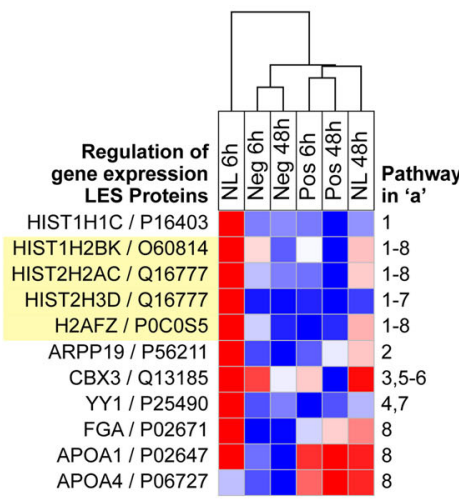

\begin{tabular}{llllll}
\hline Circle area $=$ NES & 21 & 1.5 & 11 & 0.5
\end{tabular}

$\begin{array}{rcccc}\text { Enriched in 1st condition } & & 0 & 0 & \circ \\ \text { Enriched in 2nd condition } & \bigcirc & 0 & 0 & \circ \\ \text { Fill color= FDR } & <0.001 & <0.03 & <0.05 & >0.05\end{array}$

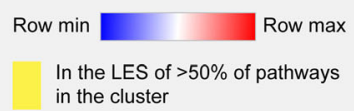

Fig. 2 Pathway enrichment in the regulation of gene expression cluster. a Bubble plot illustrating the NES and FDR across all pairwise comparisons for the eight enriched pathways in the 'regulation of gene expression' cluster. Statistically significant enrichments (FDR $<0.05)$ are shown as filled circles. $\mathbf{b}$ Heat map showing the mean LFQ intensity across lens conditions for all LES proteins contributing to the enrichment of one or more pathways in the cluster. Note that, because the 'cellular senescence' pathway was significantly enriched across multiple pairwise comparisons, the LES varied

depending on the comparison being made. Full details of the LES for each comparison are provided in, Additional file 4 Figure S4

Rab7a, Rab10, Rab11b, Rab14 [79-81]) (Fig. 4c). The other two down-regulated pathways, 'integration of energy metabolism' and 'regulation of insulin secretion' had identical LES, primarily comprised of proteins linked to vesicle exocytosis (STX1A, SNAP25, STXBP1, MARCKS) and G-protein signalling (GNA11, GNG10, GNAQ) (Fig. 4d). Similar to the 'regulation of gene expression' and 'translation' clusters, positive and negative lens-wear appeared to induce an earlier and stronger down-regulation of proteins from the mitochondrial protein import pathway (Fig. 4a).

\section{Ion and vascular homeostasis, signal transduction, and solute transport clusters}

The final three clusters of pathways, 'ion and vascular homeostasis, 'signal transduction', and 'solute transport', displayed distinct expression patterns across the three lens conditions. The three pathways related to vascular homeostasis were down-regulated in the negative relative to positive lens group at $6 \mathrm{~h}$ (sub-cluster 1 in Fig. 5a). One of these pathways (regulation of IGF by IGFBP) was also down regulated in the negative relative to positive lens group at the $48 \mathrm{~h}$. Four of the LES proteins common to these three pathways were plasma-associated (FGA, TF, APOA1, and AHSG; Fig. 5b). FGA is involved in blood clotting, TF transports iron to proliferating cells, APOA1 is a major component of high density lipoprotein (HDL), and ASHG is involved in tissue development. The most significantly down regulated pathway in this sub-cluster, 'hemostasis', also had the largest number of LES proteins. Here, a range of other proteins including GTPases (CDC42, RAP1A, NRAS), G-proteins (GNA11, GNAQ, GNG10), and ion transport proteins (particularly those involved in calcium exchange; ATP2B2, ATP2A2, SLC8A1) were implicated in the LES. Several of these ion transport proteins were also implicated in the ion homeostasis pathways that were down-regulated between 6 and $48 \mathrm{~h}$ in normally developing chicks, and up-regulated between 6 and $48 \mathrm{~h}$ in chicks wearing negative lenses (Sub-cluster 2 in Fig. 5a). In addition to proteins involved in calcium exchange, the LES of these ion homeostasis pathways included three $\mathrm{Na}^{+} / \mathrm{K}^{+}$-ATPase subunits (ATP1A2, ATP1A3, and ATP1B3) that are expected to be involved in the maintenance of cell membrane potentials [82].

Two signal transduction pathways were down-regulated between 6 and $48 \mathrm{~h}$ in normally developing no lens chicks, and a related pathway was up-regulated over the same time period in chicks wearing negative lenses (Fig. 5a). The LES of the two pathways that were down-regulated during normal development included a range of proteins involved in glutamate and GABA signalling (Fig. 5c). The glutamate-related proteins included glutaminase (GLS), which catalyses the conversion of glutamine to glutamate, 
a

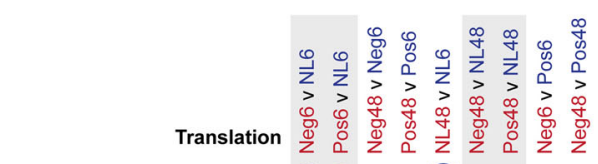

(1) Peptide chain elongation $\mathrm{OOOOO} 000$

(2) rRNA processing $\bigcirc \bigcirc \bigcirc \bigcirc \bigcirc 0000$

(3) Viral mRNA translation $\mathrm{O} 0000000$

(4) Eukaryotic translation termination $\mathrm{O} O \mathrm{OO} 000$

(5) Selenocysteine synthesis $\mathrm{OOOOO} 000$

(6) Major pathway of rRNAprocessing
in the nucleolus and cytosol $\mathrm{OO} \bigcirc \bigcirc 000$

(7) rRNA processing in the
nucleus and cytosol $\mathrm{OO} \bigcirc \bigcirc 000$

(8) SRP-dependent cotranslational
protein targeting to membrane $\mathrm{OOOO} 000$

(9) Eukaryotic translation
elongation $\mathrm{OOOOO} \circ \mathrm{O}$

(10) Selenoamino acid metabolism $\bigcirc \bigcirc 00 \bigcirc 0000$

(11) Eukaryotic translation initiation $\mathrm{O} O \mathrm{OO} 00 \circ 0$

(12) GTP hydrolysis and joining of
the 60 s ribosomal subunit $\bigcirc \bigcirc \bigcirc \bigcirc \bigcirc \circ \circ 0$

(13) Formation of a pool $\bigcirc \bigcirc 0 \bigcirc 000$

of free 40s subunits $\bigcirc \bigcirc 0 \bigcirc \bigcirc 0000$

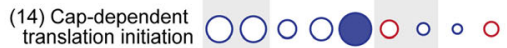

(15) L13A-mediated translational
Le

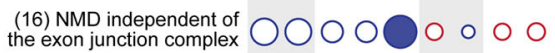

(17) $3^{\prime}$ - UTR-mediated
translational regulation $\bigcirc \bigcirc \bigcirc \bigcirc \bigcirc \circ \circ \circ$

(18) Nonsense-mediated
decay (NMD) $\bigcirc \bigcirc \bigcirc \bigcirc \bigcirc \circ \bigcirc 0$

(19) NMD enhanced by
the exon junction complex

(20) Translation initiation $\mathrm{c}$ complex formation $\bigcirc \bigcirc \bigcirc \bigcirc 000$

(21) Ribosomal scanning and
start codon recognition $\bigcirc \circ \bigcirc \bigcirc \bigcirc \circ \circ \bigcirc$

$\begin{array}{rlllll}\text { start codon recognition } & 0 \\ \text { (22) Translation } 0000000 & 0 & 0\end{array}$
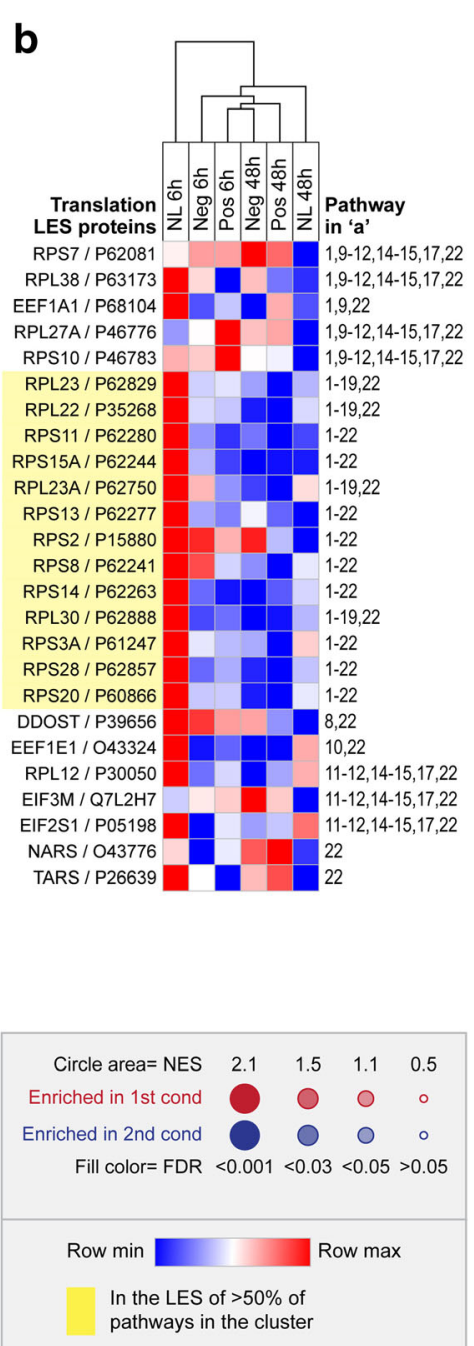

Fig. 3 Pathway enrichment in the translation cluster. a Bubble plot illustrating the NES and FDR across all pairwise comparisons for the twentytwo enriched pathways in the 'translation' cluster. Statistically significant enrichments (FDR $<0.05$ ) are shown as filled circles. b Heat map showing the mean LFQ intensity across lens conditions for all LES proteins contributing to the enrichment of one or more pathways in the cluster

and the sodium and potassium dependent glutamate transporters EAAT1 (SLC1A3) and EAAT4 (SLC1A6). The GABA-related proteins included GABA(A) Receptor Subunit Alpha-2 (GABRA2), transporters involved in GABA removal from the synaptic cleft and uptake into synaptic vesicles (GAT1, encoded by SLC6A1, and VGAT, encoded by SLC32A1), and the GABA Aminotransferase (ABAT), which catalyses the conversion of GABA to succinate semialdehyde. The LES of the related signal transduction pathway that was up-regulated between 6 and $48 \mathrm{~h}$ in chicks wearing negative lenses contained only one GABA receptor sub-unit (GABRA2), with the remainder of the LES comprised of Neurofilament light polypeptide (NEFL) that forms a major component of axon cytoskeletons, N-ethylmaleimide-sensitive factor (NSF) that is involved in membrane fusion, a catalytic subunit of cAMP-dependent protein kinase (PRKACB), and
Neuroplastin (NPTN), which is involved in cell-cell interactions (Fig. 5c).

The final cluster was related to solute transport (Fig. 5a). Here, the 'transport of inorganic cation, anions, and amino acids/oligopeptides' pathway was down-regulated between 6 and $48 \mathrm{~h}$ in no lens chicks. The LES of this pathway included several of the glutamate, GABA, and $\mathrm{Na}^{+} / \mathrm{Ca}^{++}$ transporters from the ion and vascular homeostasis and signal transduction clusters, as well as bicarbonate transporters (SLC4A10, SLC4A4), an amino acid exchanger (SLC7A5), and a mitochondrial glutamate carrier (SLC25A22) (Fig. 5d). The second pathway from the solute transport cluster, 'SLC-mediated transmembrane transport', was up-regulated in the positive lens group relative to the no lens group at $48 \mathrm{~h}$. This pathway had a highly similar LES to the solute transport pathway that was down-regulated over time in the no lens group, including 


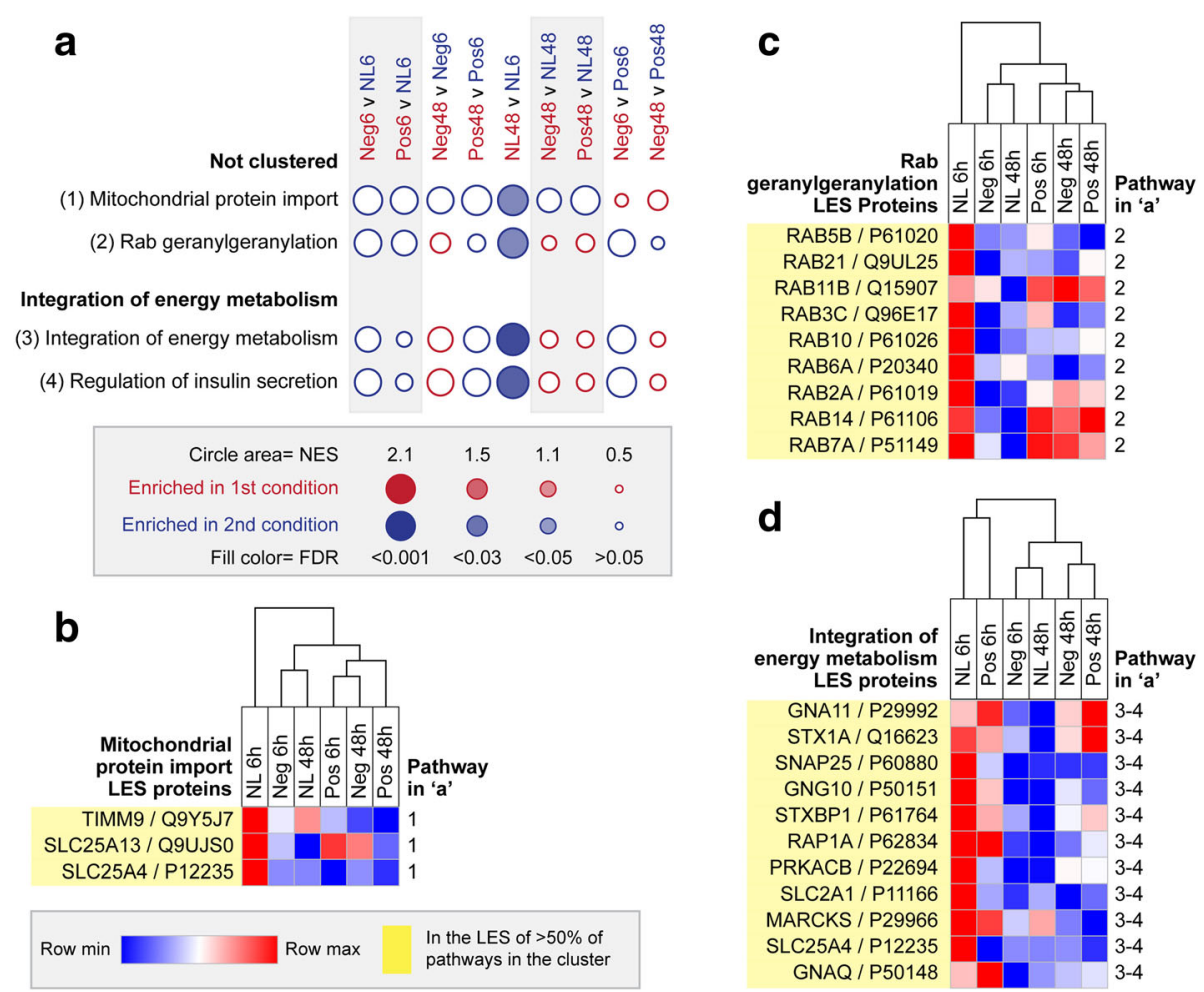

Fig. 4 Pathway enrichment in mitochondrial protein import, rab GTPase, and integration of energy metabolism clusters. a Bubble plot illustrating the NES and FDR across all pairwise comparisons for the four enriched pathways in the 'mitochondrial protein import', rab GTPase and 'integration of energy metabolism' clusters. Statistically significant enrichments (FDR $<0.05)$ are shown as filled circles. Heat maps show the mean LQF intensity across lens conditions for all LES proteins contributing to the enrichment of one or more pathways in the $\mathbf{b}$ mitochondrial protein import, c rab GTPase and $\mathbf{d}$ integration of energy metabolism clusters

glutamate transporters (SLC1A6, SLC1A3), bicarbonate transporters (SLC4A10, SLC4A4), and sodium-calcium (SLC8A1) and amino acid (SLC1A4, SLC7A5) exchangers (Fig. 5d).

\section{Cross-pathway interactions}

To better understand interactions between the nine implicated pathway clusters, we created a protein-protein interaction (PPI) network for the LES proteins from all significant pathway enrichments. This PPI network demonstrated extensive interactions between the LES from different pathway clusters (Fig. 6). Topological analysis highlighted several nucleocytoplasmic transport proteins (PRKCAB, POLR2C, UBE2I and KPNB1), the hemostasis pathway protein $\mathrm{CDC} 42$, and the ribosomal protein RPS3A as having potential to exert a high degree of control over the interactions of other nodes in the network (termed 'betweenness centrality') [83].

\section{Discussion}

This study has compared protein abundance in the chick retina/RPE during normal development and lens-induced myopia and hyperopia. We specifically aimed to elucidate how lens-wear affects normal developmental processes and to identify pathways showing bidirectional and/or distinct expression responses across the lens conditions as such pathways are likely to be involved in directional ocular growth, and may be of interest as therapeutic targets. Seventy-one Reactome pathways linked to cell development and neuronal maturation were differentially enriched between $6 \mathrm{~h}$ (P5) and 48 h (P7) in no lens animals. Lens-wear disrupted most of these normal developmental changes, and induced lens-specific shifts in a subset of pathways related to neurotransmission (particularly GABA and glutamate signalling), calcium homeostasis, and ATP-driven ion transport.

\section{Developmental pathways in no lens chicks}

The range of protein abundance changes that we identified between 6 and $48 \mathrm{~h}$ in no lens chicks was broadly consistent with maturation and the consequent slowing of cell growth as the retina develops post-hatch [78, 84]. Histone and translational pathways were down-regulated between 6 and $48 \mathrm{~h}$, and nucleoporin and heat shock-related pathways were up-regulated over the same time period. These pathways are closely linked to developmental processes, such as histone protein synthesis that is needed to package replicated DNA into 
a

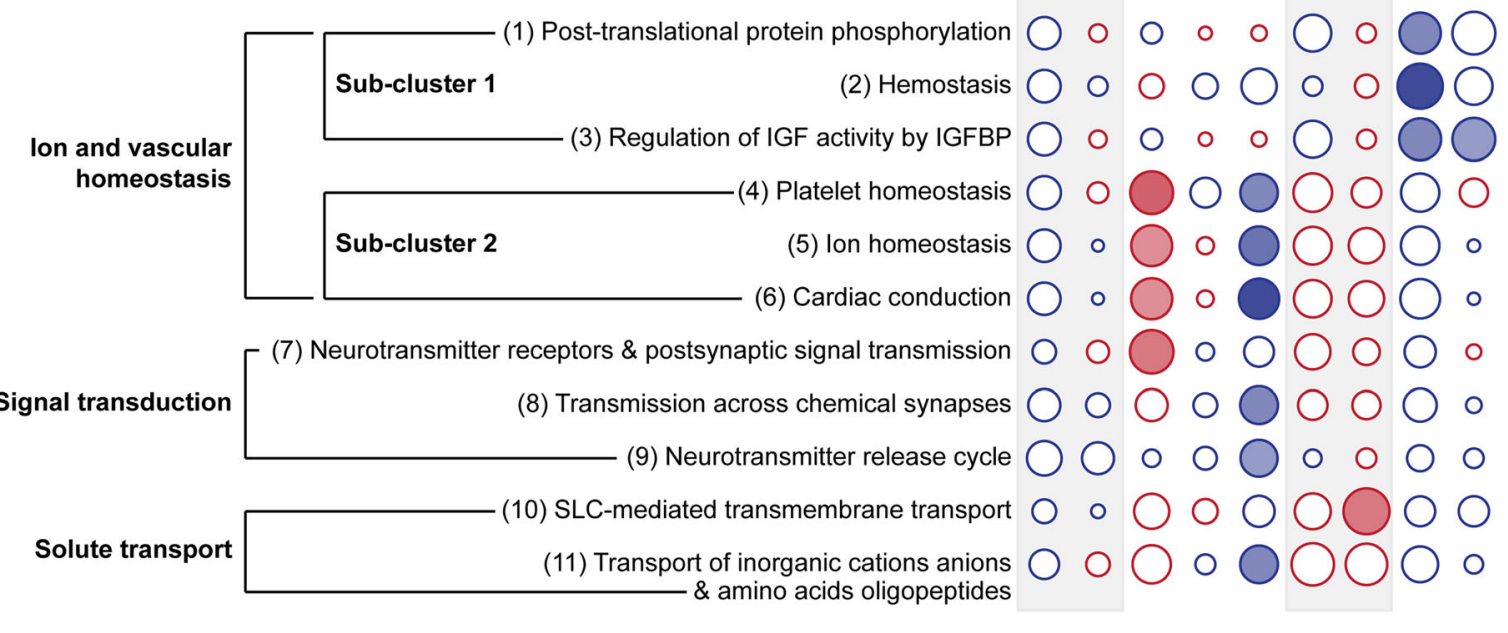

b

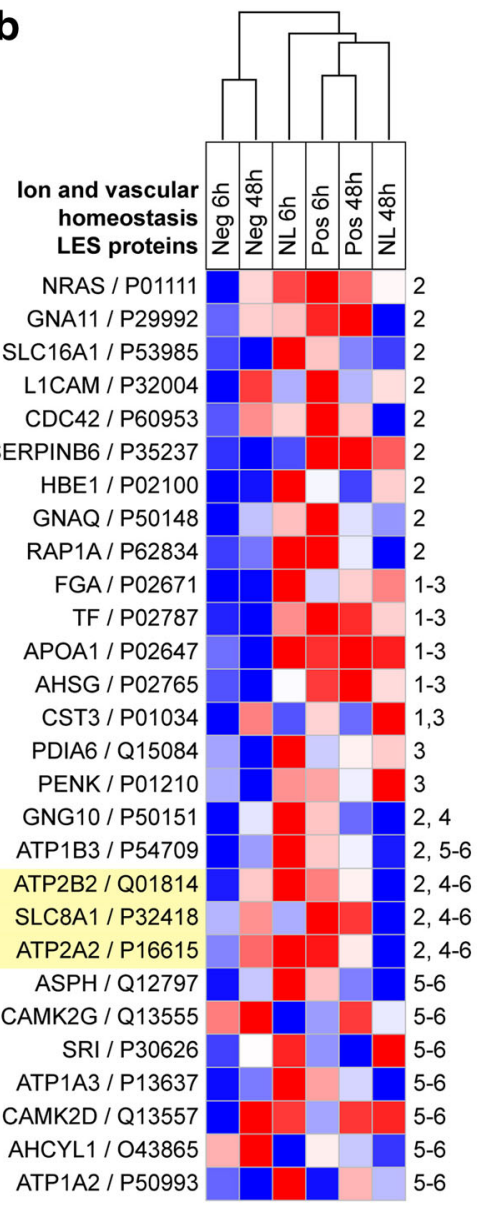

C

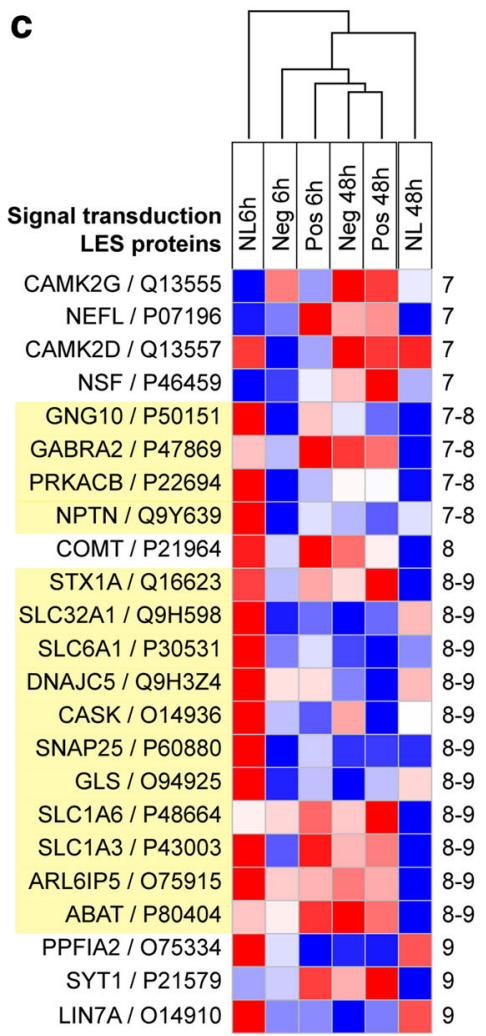

d

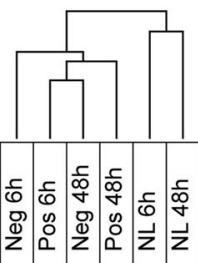

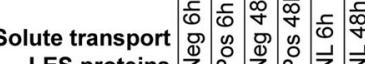

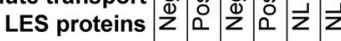

NUP153/P49790

NUP54 / Q7Z3B4

SLC1A4 / P43007

SLC1A6/ P48664

SLC8A1 / P32418

SLC4A10 / Q6U841

SLC7A5 / Q01650

SLC1A3/P43003

SLC4A4 / Q9Y6R1

SLC25A22 / Q9H936

SLC32A1 / Q9H598

AHCYL2 / Q96HN2

\section{Key for a}

Circle area $=$ NES $\quad 2.1 \quad 1.1 \quad 0.5$

Enriched in 1st cond

Enriched in 2nd cond

Fill color= FDR $\quad<0.001<0.05>0.05$

\section{Key for b-d}

Row min Row max

In the LES of $>50 \%$ of

pathways in the cluster

Fig. 5 (See legend on next page.) 
(See figure on previous page.)

Fig. 5 Pathway enrichment in ion and vascular homeostasis, signal transduction, and solute transport clusters. a Bubble plot illustrating the NES and FDR across all pairwise comparisons for the eight enriched pathways in the 'ion and vascular homeostasis', 'signal transduction', and 'solute transport' clusters. Statistically significant enrichments (FDR $<0.05)$ are shown as filled circles. Heat maps show the mean LFQ intensity across lens groups for all proteins that were in the LES of one or more enriched pathways in the $\mathbf{b}$ ion and vascular homeostasis, $\mathbf{c}$ signal transduction and $\mathbf{d}$ solute transport clusters. Note that the LES varied across pathways that were significantly enriched in multiple lens groups (i.e., several of the ion and vascular homeostasis pathways). Full details of the LES for each comparison are provided in, Additional file 4 Figure S5

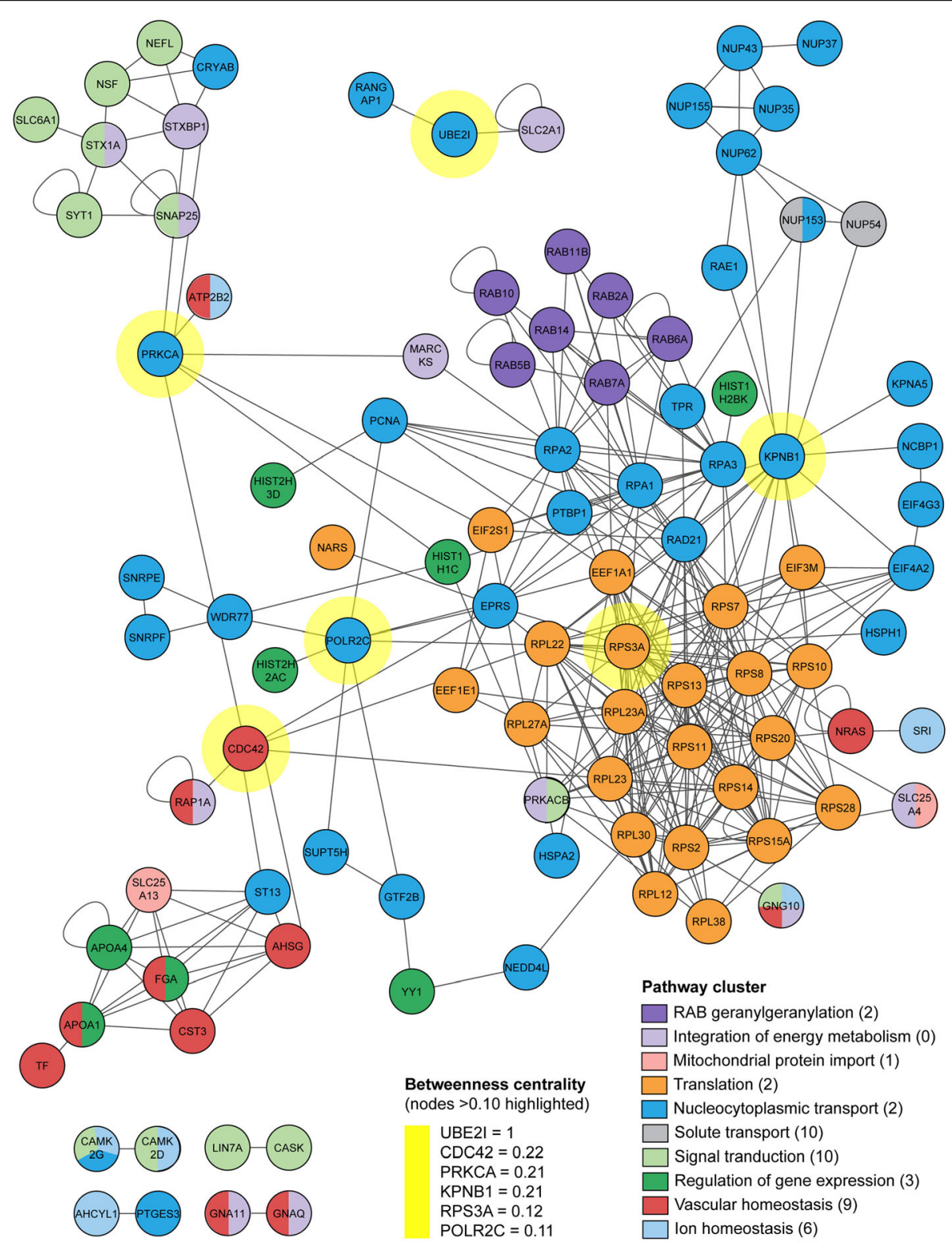

Fig. 6 Interactions between leading edge subset proteins. A protein-protein interaction (PPI) network for the LES proteins from all significant pathway enrichments was generated in Cytoscape. Proteins in the network are coloured according to pathway cluster from the GSEA, and connections between proteins indicate a protein-protein interaction. Topological analysis was used to identify proteins with a high degree of betweenness centrality (i.e., proteins that connect subnetworks within the interaction diagram). These key proteins are highlighted in yellow. LES proteins with no interactions are not shown in the diagram. The number of LES proteins not shown for each cluster is indicated in parenthesis after the cluster name in the 'pathway cluster' key 
chromatin during cell cycle progression $[85,86]$ and the ribosome content of a cell which determines its capacity for protein production and associated growth [87-89]. Heat shock [90] and nucleocytoplasmic transport pathways $[91,92]$ are also involved in the dynamic regulation of gene and protein expression during development, and both of these pathways are closely tied to ribosomal biogenesis and translational processes [93-95].

Proteins from a range of ion homeostasis and signalling pathways were also down-regulated between P5 and P7 in the no lens group, as would be expected in chicks with plano refraction undergoing normal post-hatch refinement of neuronal networks [78]. The LES of these pathways was composed primarily of GABA and glutamate transporters and receptor subunits, rab GTPases linked to insulin and glucose signalling, and $\mathrm{Ca}^{++}$and $\mathrm{Na}^{+} / \mathrm{K}^{+}$transporting ATPases. Proteins from calcium-related signalling pathways were also implicated, including those involved in vesicle exocytosis and G-protein signalling. Past research has demonstrated close interconnections between these GABA, glutamate, glucose, insulin, and calcium signalling pathways during neuronal development [96-99].

\section{Positive and negative lenses disrupt the timing of normal developmental shifts}

Up-regulation of nucleocytoplasmic transport pathways between 6 and $48 \mathrm{~h}$ was preserved in the positive lens group, however, lens-wear (of both signs) disrupted the timing, strength, and/or direction of all of the other expression shifts seen in normally developing no lens animals. In most cases (i.e., for pathways from 'regulation of gene expression', 'translation', and 'mitochondrial protein import' clusters) this appeared to occur because lens-wear of both signs induced a premature down-regulation of pathway expression relative to that seen in no lens animals (i.e., the pathways were down-regulated in lens relative to no lens groups at $6 \mathrm{~h}$, and then further down-regulated over time between 6 and $48 \mathrm{~h}$ in both lens groups). These non-specific responses primarily affected pathways linked to basic cellular processes (such as histone proteins, ribosomal subunits, and translation elongation factors) which are known to be down-regulated in response to multiple types of cellular stress [e.g. 85, 100, 101, 102]. Such stress-related expression responses are usually associated with a slowing of the cellular growth rate $[100,101]$, which helps to explain the pattern of overlap with pathway down-regulation in no lens chicks where normal post-hatch developmental processes are also expected to be slowing down [78, 84]. The general stress response is aimed at increasing cellular tolerance limits under adverse conditions, and allowing time for adaptive responses specific to the stressor to re-establish homeostasis [102]. Thus, although these non-specific shifts presumably reflect some secondary effect of lens-wear (such as physiological stress resulting from blur or peripheral occlusion by the Velcro ring), they could still be involved in priming the system for growth-specific changes (for example by down-regulating ribosomal biogenesis in order to conserve metabolic energy for use in homeostatic lens-specific adaptations to neurotransmission).

\section{Lens-wear induces distinct expression patterns in pathways related to neurotransmission and ion homeostasis}

In addition to these non-specific changes, lens-wear induced distinct growth-specific expression patterns in a small number of pathways primarily related to neurotransmission and ion homeostasis. As discussed briefly above, 'Transmission across chemical synapses' and 'neurotransmitter release cycle' pathways were down-regulated between P5 and P7 in normally developing chicks. Many of the core proteins in these pathways were involved in glutamatergic (GLS, SLC1A3, SLC1A6) or GABAergic (GABRA2, SLC6A1, SLC32A1, ABAT) signalling. Previous studies have similarly demonstrated changes in the expression of GABA and glutamate pathway genes and proteins in the retina during normal post-natal emmetropization, including $\mathrm{GABA}_{\mathrm{A}}$ receptor subunits [103], the ABAT GABA aminotransferase [57], and glutamate carrier subunits [69].

In contrast to the no lens condition, the 'neurotransmitter receptors and postsynaptic signal transmission' pathway was enriched between 6 and $48 \mathrm{~h}$ in the myopia induction condition, suggesting an up-regulation of aspects of neurotransmission (particularly GABA signalling) during the mid to late stages of refractive compensation to $-10 \mathrm{D}$ lenses. The core proteins responsible for this enrichment included the $\mathrm{GABA}_{\mathrm{A}}$ receptor subunit alpha 2 (GABRA2) and N-ethylmaleimide-sensitive factor (NSF), which is involved in $\mathrm{GABA}_{\mathrm{A}}$ receptor subunit trafficking to the plasma membrane [104]. Several proteins linked to the regulation of synapse organization and strength were also implicated. Some previous studies have reported down-regulation of GABA-related genes or retinal GABA content during lens and occlusion myopia induction [51, $58,105,106]$, however, most reports are consistent with the increase in GABA pathway signalling suggested here. Specifically, the present findings are in agreement with previous reports of up-regulation of the NSF protein during lens-induced myopia in mouse [63], and up-regulation of the $\mathrm{GABA}_{\mathrm{A}}$ receptor mRNA and protein [107] and increased retinal GABA content during lens-induced myopia in guinea pigs $[107,108]$. This pattern of expression responses is also consistent with drug studies showing that GABA receptor antagonists inhibit myopia development $[105,109,110]$. Similarly, the GABA $_{C}$ receptor antagonist TPMPA enhanced the protective effect of short periods of normal vision on myopia development in chick, and the 
$\mathrm{GABA}_{\mathrm{A} / \mathrm{C}}$ agonist Muscimol inhibited the protective effect of normal vision [111].

Changes to the expression of GABA, glutamate, and synaptic proteins between 6 and $48 \mathrm{~h}$ in no lens and negative lens groups are suggestive of activity-dependent 'tuning' of retinal signalling [112]. Calcium influx into cells provides a ubiquitous 'activity signal' that is crucial for such synaptic plasticity and, in accordance with this, pathways related to the maintenance of ion homeostasis displayed the same expression patterns as the signal transduction pathways in no lens and negative lens groups. Specifically, 'ion homeostasis', 'platelet homeostasis' and 'cardiac conduction' pathways were up-regulated between 6 and $48 \mathrm{~h}$ in the negative lens group, and down-regulated between 6 and $48 \mathrm{~h}$ in the no lens group. The core proteins in these pathways were predominantly related to calcium regulation, including $\mathrm{Ca}^{++}$ transporting ATPases (ATP2B2 and ATP2A2), the NCX1 $\mathrm{Na}^{+} / \mathrm{Ca}^{++}$exchanger (SLC8A1), sorcin (SRI) [113], aspartate beta-hydroxylase (ASPH) [114], and both the gamma and delta subunits of calcium/calmodulin-dependent protein kinase II (an enzyme complex known to drive activity-dependent changes in synapse strength $[115,116])$. GABA and glutamate transporters are reliant on $\mathrm{Na}^{+} / \mathrm{K}^{+}$-ATPase to generate the ion gradients that drive transmitter uptake $[117,118]$ and, in accordance with this, $\mathrm{Na}^{+} / \mathrm{K}^{+}$-ATPase subunits were also among the core proteins implicated in the ion homeostasis pathways. Interestingly, $\mathrm{Na}^{+} / \mathrm{K}^{+}$-ATPase inhibition with Ouabain has been shown to prevent compensation to lenses in chick [119]. Our previous RNA-sequencing study has also identified up-regulation of mitochondrial oxidative phosphorylation genes in the retina/RPE/choroid of chicks of the same age following 2 days of negative lens-wear [57]. Considered together with the concurrent up-regulation of ATP-dependent ion transporters and GABA-related signalling proteins during negative lens-wear in the present study, these findings suggest a close relationship between shifts in neurotransmission, cellular ion homeostasis, and the associated utilization of cellular energy resources during myopia induction.

Negative lens-wear also induced a down-regulation of several pathways related to ion and vascular homeostasis at $6 \mathrm{~h}$ ('post-translational protein phosphorylation,' 'hemostasis', and 'regulation of IGF by IGFBP'), resulting in their enrichment in the positive relative to the negative lens group. The core proteins in these pathways were disparate, but notably included $\mathrm{Ca}^{++}$transporting ATPases (ATP2B2 and ATP2A2) and the NCX1 $\mathrm{Na}^{+} / \mathrm{Ca}^{++}$exchanger (SLC8A1), as well as three of the four plasma-related proteins recently shown to be up-regulated in chick vitreous following negative lens-wear relative to positive lens-wear (APOA1, TF, and CST3) [120]. The plasma-related proteins remained down-regulated in the negative lens group at $48 \mathrm{~h}$, while calcium-related proteins were up-regulated between 6 and $48 \mathrm{~h}$ (as discussed above). This shift in calcium regulation between the early and late time-points is notable, and perhaps related to the divergent expression of glutamate and GABA pathway mRNA previously reported between $6 \mathrm{~h}$ and $72 \mathrm{~h}$ time-points in the chick negative lens model [51].

Positive lens-wear, by comparison, inhibited the normal down-regulation of solute transport proteins between 6 and $48 \mathrm{~h}$. This resulted in enrichment of the 'SLC-mediated transmembrane transport' pathway in the positive lens group relative to the no lens group at $48 \mathrm{~h}$. The core proteins driving this enrichment included EAAT1 (SLC1A3) and EAAT4 (SLC1A6) glutamate transporters. EAAT1 (also known as GLAST) is the predominant glutamate transporter in the retina. It is localized on Muller cells [121], and is essential for the glutamate-glutamine cycle [122]. EAAT4 is localized on the photoreceptor outer segments [123]. Both of these transporters clear glutamate from the extracellular space, a function important for maintaining an accurate representation of the light signal. Also implicated were the sodium-driven chloride bicarbonate exchanger NCBE (SLC4A10) and the sodium-bicarbonate cotransporter NBCE1 (SLC4A4). $\mathrm{NCBE}$ is thought to act together with KCC2 to maintain low intracellular chloride in OFF bipolar cell dendrites and ON bipolar cell terminals, thus supporting the hyperpolarizing action of GABA [124, 125]. NCBE knockout mice display decreased contrast sensitivity and visual acuity, and deceased ON bipolar cell activity [124]. NCBE1 is expressed on Muller cells and apical membrane of the $\mathrm{RPE}$, and is thought to regulate light-induced extracellular alkalosis [126].

These expression changes in the positive lens group are suggestive of differences in the sensitivity of retinal signalling pathways, particularly at photoreceptor-bipolar synapses. It is possible that these expression changes are an adaptation to the decrease in expression of photoreceptor proteins that we have previously reported following $6 \mathrm{~h}$ of positive lens-wear in this dataset [66]. The need for signalling adaptations at the photoreceptor-bipolar level is predicted by our RIDE model [77] and consistent with pharmacological and gene knockout studies showing that changes to the balance of ON and OFF bipolar signalling can affect post-natal ocular growth and the induction of optically-induced refractive errors [38, 127-133]. Recent genetic studies have also strongly implicated photoreceptor and bipolar cell signalling in the development of refractive errors in humans $[75,76]$.

\section{Conclusions}

This study has shown that positive and negative lens-wear induces the premature down-regulation of a range of basic housekeeping pathways in the retina/RPE. 
These non-specific expression shifts are presumably driven by the secondary effects of lens-wear, and could represent a general stress response with the potential to promote lens-specific homeostatic adaptations. A smaller number of pathways displayed distinct expression profiles across the lens conditions. These latter findings provide support for past research suggesting that GABAergic signalling is up-regulated during myopia induction [63, 105, 107-111]. Changes in the expression of ion transport and binding proteins, particularly those related to calcium regulation and $\mathrm{Na}-\mathrm{K}$-ATPase, further supports the existence of theoretically expected links between shifts in neurotransmission, ion homeostasis, and energy requirements $[57,58,106]$ during lens-induced myopia. Previous $\mathrm{x}$-ray microanalysis and microarray studies have reported retinal hyperosmolarity and similar pathway expression shifts following occlusion myopia in chick [58, 134, 135], suggesting a similar molecular basis for lens and occlusion myopia models (in line with past research e.g. [31, 70]). Our findings also provide novel evidence for changes to glutamate and bicarbonate/chloride transport during hyperopia induction, with potential implications for signalling at the photoreceptor-bipolar synapse. Overall, these findings reflect a key role for perturbed neurotransmission and associated ion homeostasis in optically induced ocular growth changes, as predicted by our RIDE model [77].

\section{Methods}

\section{Generation and pre-processing of LC-ESI-MS/MS data}

The methods used to generate the LC-ESI-MS/MS data analysed in this study have been described in our previous publication [66]. Briefly, 31 male chicks (Leghorn/ New Hampshire) were assigned to a lens condition (right eye +10 dioptre (D), right eye $-10 \mathrm{D}$, or no lens) on P5. Lenses were attached with Velcro, and lensing was staggered so that subsequent data collection time-points were circadian matched. Separate no lens controls were used because monocular treatments can affect blood flow [136, 137], refraction and axial length [28, 138], and gene and protein expression in the fellow eye $[138,139]$. Furthermore, we used right eyes only because chicks are oriented in the embryo such that the left eye is occluded while the right eye receives light stimulation. This produces developmental asymmetries within the left and right visual pathways of young male chicks following hatching [140-142].

Following 6 h (P5) or 48 h (P7) of lens-wear, chicks were anaesthetized (ketamine, $45 \mathrm{mg} / \mathrm{kg}$; xylazine, $4.5 \mathrm{mg} / \mathrm{kg}$ i.m.) and their right eye refraction and axial dimensions were measured via manual retinoscopy (Keeler, Vista Diagnostic Instruments, Windsor, UK) and a-scan ultrasonography (7 MHz probe; A-Scan III, TSL: Teknar, Inc., St Louis, MO). Biometric data was not recorded for the unused left eyes in order to minimize time under anaesthesia prior to tissue collection. The chicks were then euthanized via decapitation, and the retina/RPE was immediately collected from the right eye for LC-ESI-MS/MS analysis. All procedures adhered to the ARVO Statement for the use of Animals in Ophthalmic and Vision Research and were conducted in accordance with approved La Trobe University Animal Ethics Committee protocols (AEC14-60).

Retina/RPE samples from 5 chicks per condition were analysed individually using LC-ESI-MS/MS, with the exception of the no lens $48 \mathrm{~h}$ condition where tissue from 6 chicks was profiled. Samples were re-suspended in digestion buffer ( $8 \mathrm{M}$ urea, $50 \mathrm{mM}$ ammonium bicarbonate, $10 \mathrm{mM}$ DTT) and incubated for $5 \mathrm{~h}$. Samples were centrifuged, and the soluble fraction was used for protein concentration determination. Each sample $(50 \mu \mathrm{g}$ protein) was adjusted to $100 \mu \mathrm{l}$ with digestion buffer, and $55 \mathrm{mM}$ iodoacetamide was then added to alkylate thiol groups for $35 \mathrm{~min}$. The preparation was diluted to $1 \mathrm{M}$ urea with $25 \mathrm{mM}$ ammonium bicarbonate, and trypsin was added to a $5 \mu \mathrm{M}$ final concentration for overnight digests. The digests were acidified with $1 \%(v / v)$ trifluoroacetic acid (TFA) and the peptides desalted on SDB-XC Empore StageTips (3 M Company, St. Paul, MN) and dried in a SpeedVac centrifuge as described previously [143]. Peptides were reconstituted in 0.1\% TFA and 2\% acetonitrile (ACN), loaded onto trapping columns $\left(\mathrm{C}_{18}\right.$ PepMap $100 \mu \mathrm{m}$ ID $\times 2 \mathrm{~cm}$, Thermo-Fisher Scientific, San Jose, CA) at $5 \mu \mathrm{l} / \mathrm{min}$ for $6 \mathrm{~min}$, and washed for $6 \mathrm{~min}$ before switching the pre-column in line with the analytical column (Vydac MS $\mathrm{C}_{18}, 3 \mu \mathrm{m}, 300 \AA$ and 75 $\mu \mathrm{m}$ ID $\times 25 \mathrm{~cm}$, Grace Pty. Ltd., Columbia, MD). The separation of peptides was performed at $300 \mathrm{nl} / \mathrm{min}$ using a linear ACN gradient of buffer A (0.1\% formic acid, $2 \%$ $\mathrm{ACN})$ and buffer B $(0.1 \%$ formic acid, $80 \% \mathrm{ACN})$, starting at $5 \%$ buffer B to $55 \%$ over $120 \mathrm{~min}$. Data were collected on an Orbitrap Elite (Thermo-Fisher Scientific) in Data Dependent Acquisition mode using m/z 300-1500 as MS scan range. Collision-induced dissociation (CID) MS/MS spectra were collected for the 20 most intense ions per MS scan. The dynamic exclusion parameters used were: repeat count 1 , duration $90 \mathrm{~s}$ and the exclusion list size was set at 500 with early expiration disabled. Other instrument parameters for the Orbitrap Elite were as follows: MS scan at 120000 resolution, maximum injection time $150 \mathrm{~ms}$, automatic gain control (AGC) target $1 \times 10^{6}$, CID at $35 \%$ energy for a maximum injection time of $150 \mathrm{~ms}$ with AGT target of 5000. The instrument was operated in dual analyser mode with the Orbitrap analyser being used for MS and the linear trap being used for MS/MS.

Identification and label-free quantification of proteins was performed on the raw output files from LC-ESI-MS/ MS using MaxQuant (Version 1.5.1.6; [144, 145]) and the 
Table 2 Description of GSEA metrics

\begin{tabular}{ll}
\hline Metric & Description \\
\hline Enrichment score (ES) & $\begin{array}{l}\text { Reflects the degree to which proteins in a pathway are over-represented at the top } \\
\text { or bottom of the ranked protein list. }\end{array}$ \\
Normalized enrichment score (NES) & $\begin{array}{l}\text { A normalized version of the enrichment score that accounts for differences in pathway size. } \\
\text { This is the primary statistic for comparing results across pathways. } \\
\text { False discovery rate (FDR) }\end{array}$ \\
$\begin{array}{l}\text { The probability that a pathway with a given NES represents a false positive finding. An FDR } \\
\text { cut-off of 5\% was used to determine statistical significance in the present study. }\end{array}$ \\
$\begin{array}{l}\text { Proteins that appear in the ranked list at or before the point that the running ES reaches its } \\
\text { maximum deviation from zero. These are the core proteins driving pathway enrichment. } \\
\text { In the present study, LES proteins were used to group similar pathway findings into clusters } \\
\text { (thus reducing redundancy and aiding with interpretation). }\end{array}$ \\
\hline
\end{tabular}

Andromeda search engine (September 2016 Gallus gallus Uniprot FASTA database). Peptides with a minimum of seven amino-acid length were considered, and the required FDR was set to $1 \%$ at the peptide and protein level. Protein group intensity values were normalized using the MaxLFQ algorithm [145] and log base 2 transformed. Flagged protein groups and protein groups with $>40 \%$ missing values in any condition were filtered from the results. The remaining missing values were imputed using a QRLIC/SVD approach (imputeLCMD R package v2.0; [146]), and the data were then normalized using the LIMMA Cyclic Loess function (package v3.30.12; [147]). Finally, to enable the use of curated human Reactome Gene Matrix Transposed (GMT) files for pathway analyses, high confidence human orthologs for each Uniprot Accession in the dataset were identified using InParanoid (v8.0) [148].

\section{Gene set enrichment analysis}

Homo sapiens GMT files for Reactome pathways (Release 37 [149]) were obtained from the Bader lab on 17-06-2017 [150]. These GMT files and the dataset of normalized $\log$ transformed LFQ intensity values mapped to human ortholog UniProt IDs were imported into the javaGSEA desktop app [151]. GSEA was used to assess Reactome pathway expression in lens relative to no lens groups at each time-point, negative relative to positive lens-groups at each time-point, and within each lens-group over time.

The first step in GSEA involves ranking all proteins in the dataset. In the present study, proteins were ranked by the difference between group means scaled by the standard deviation (the default GSEA 'signal to noise' metric). Once the dataset was ranked, the enrichment score (ES) for each pathway was calculated by walking down the ranked list of proteins, increasing the cumulative enrichment score when a protein was in the pathway, and decreasing it when it was not. The final ES for each pathway is the maximum deviation from zero of the cumulative score when walking down the ranked list and it can be interpreted as a weighted KolmogorovSmirnov statistic $[74,151]$. The significance of pathway ES's was calculated by gene set permutation. Table 2 provides a summary of the GSEA output metrics and their use in the present study.

Pathways with similar leading edge subject (LES) proteins driving their enrichment were clustered together using the Cytoscape Enrichment Map app [150] to facilitate interpretation and reduce redundancy (Additional file 3: Figure S1-S2). GSEA results (shown as bubble plots [152]) and LES analysis results (shown as heat maps) are presented separately for each pathway cluster in the results section. Hierarchical clustering (Euclidean Average Linkage method [153]) of the lens groups in each heat map was performed using the Broad Institute Morpheus web app [154].

\section{Protein-protein interaction networks}

A protein-protein interaction (PPI) network for the LES proteins from all significant pathway enrichments was generated using the Protein Interaction Network Analysis platform (PINA) Cytoscape plugin [155]. This platform integrates data from six different protein-protein interaction databases (IntAct, MINT, BioGRID, DIP, HPRD and MIPS MPact). The Cytoscape Network Analyser plugin [156] was then used to identify nodes with a high degree of betweenness centrality (i.e., proteins that connected dense subnetworks within the interaction diagram).

\section{Additional files}

Additional file 1: Table S1. Biometric measures (refraction, axial length, and vitreous chamber depth) for each sample. (XLSX 10 kb)

Additional file 2: Table S2. Pre-processed LC-ESI-MS/MS dataset. (XLSX 608 kb)

Additional file 3: Figure S1-S2. GSEA pathway clusters created using the Cytoscape Enrichment Map app. (PDF 643 kb)

Additional file 4: Figure S3-S5. Leading edge subset proteins for pairwise enrichments in the nucleocytoplasmic transport, regulation of gene expression, ion and vascular homeostasis, signal transmission, and solute transport clusters. (PDF $980 \mathrm{~kb}$ ) 


\section{Acknowledgements}

The authors would like to thank Melanie Murphy and Loretta Giummarra for their assistance with biometric data collection, and Rachael Downs for preparing the samples.

\section{Funding}

This research was supported by a La Trobe University RFA Understanding Disease Start-up Grant

\section{Availability of data and materials}

The datasets supporting the conclusions of this article are included within the article (and its additional files). The mass spectrometry proteomics data have been deposited to the ProteomeXchange Consortium via the PRIDE partner repository with the dataset identifier PXD008818 and https://doi.org/ 10.6019/PXD008818.

\section{Authors' contributions}

NR and SC conceived and designed the study, reared the animals, collected the biometric data and extracted the tissue. PF conducted the LC-ESI-MS/MS analysis. NR analysed the data, prepared the figures, and drafted the manuscript. All authors made critical revisions to the manuscript, and approved the final version.

\section{Ethics approval}

The protocols used in this study were approved by the La Trobe University Animal Ethics Committee under application number AEC14-60.

\section{Consent for publication}

Not applicable.

\section{Competing interests}

The authors declare that they have no competing interests.

\section{Publisher's Note}

Springer Nature remains neutral with regard to jurisdictional claims in published maps and institutional affiliations.

\section{Author details}

'Department of Psychology and Counselling, School of Psychology and Public Health, La Trobe University, Plenty Rd., Bundoora, Melbourne, VIC 3083, Australia. ${ }^{2}$ Department of Biochemistry and Genetics, La Trobe Institute for Molecular Sciences, La Trobe University, Melbourne, VIC, Australia.

\section{Received: 24 February 2018 Accepted: 16 August 2018}

\section{Published online: 29 August 2018}

\section{References}

1. Holden BA, Fricke TR, Wilson DA, Jong M, Naidoo KS, Sankaridurg P, et al. Global prevalence of myopia and high myopia and temporal trends from 2000 through 2050. Ophthalmology. 2016;123(5):1036-42.

2. Flitcroft DI. The complex interactions of retinal, optical and environmental factors in myopia aetiology. Prog Retin Eye Res. 2012;31(6):622-60.

3. Saw SM, Gazzard G, Shih-Yen EC, Chua WH. Myopia and associated pathological complications. Ophthalmic Physiol Opt. 2005;25(5):381-91.

4. Wong TY, Ferreira A, Hughes R, Carter G, Mitchell P. Epidemiology and disease burden of pathologic myopia and myopic choroidal neovascularization: an evidence-based systematic review. Am J Ophthalmol. 2014;157(1):9-25. e12

5. Buch H, Vinding $T$, La Cour M, Appleyard M, Jensen GB, Nielsen NV. Prevalence and causes of visual impairment and blindness among 9980 scandinavian adults: the Copenhagen city eye study. Ophthalmology. 2004; 111(1):53-61.

6. Cotter SA, Varma R, Ying-Lai M, Azen SP, Klein R. Los Angeles Latino eye study G. Causes of low vision and blindness in adult latinos: the los Angeles latino eye study. Ophthalmology. 2006;113(9):1574-82.

7. Xu L, Wang Y, Li Y, Wang Y, Cui T, Li J et al. Causes of blindness and visual impairment in urban and rural areas in beijing: The beijing eye study. Ophthalmology. 2006;113(7):1134 e1-11.

8. Grosvenor T. Refractive component changes in adult-onset myopia: evidence from five studies. Clin Exp Optom. 1994;77(5):196-205.

9. Strang NC, Schmid KL, Carney LG. Hyperopia is predominantly axial in nature. Curr Eye Res. 1998;17(4):380-3.
10. Wildsoet CF. Active emmetropization--evidence for its existence and ramifications for clinical practice. Ophthalmic Physiol Opt. 1997;17(4):279-90.

11. Norton TT, McBrien NA. Normal development of refractive state and ocular component dimensions in the tree shrew (tupaia belangeri). Vis Res. 1992; 32(5):833-42.

12. Bradley DV, Fernandes A, Lynn M, Tigges M, Boothe RG. Emmetropization in the rhesus monkey (macaca mulatta): birth to young adulthood. Invest Ophthalmol Vis Sci. 1999;40(1):214-29.

13. Irving EL, Sivak JG, Curry TA, Callender MG. Chick eye optics: zero to fourteen days. J Comp Physiol A. 1996;179(2):185-94.

14. Norton TT, Siegwart JT Jr. Animal models of emmetropization: matching axial length to the focal plane. J Am Optom Assoc. 1995;66(7):405-14.

15. Raviola E, Wiesel TN. An animal model of myopia. N Engl J Med. 1985; 312(25):1609-15

16. Wallman J, Turkel J, Trachtman J. Extreme myopia produced by modest change in early visual experience. Science. 1978;201(4362):1249-51.

17. Tejedor J, de la Villa P. Refractive changes induced by form deprivation in the mouse eye. Invest Ophthalmol Vis Sci. 2003;44(1):32-6.

18. Norton T, Rada JA. Reduced extracellular matrix in mammalian sclera with induced myopia. Vis Res. 1995;35(9):1271-81.

19. Troilo D, Nickla DL. The response to visual form deprivation differs with age in marmosets. Invest Ophthalmol Vis Sci. 2005;46(6):1873-81.

20. Hung LF, Wallman J, Smith EL 3rd. Vision-dependent changes in the choroidal thickness of macaque monkeys. Invest Ophthalmol Vis Sci. 2000; 41(6):1259-69.

21. Nathan J, Kiely PM, Crewther SG, Crewther DP. Disease-associated visual image degradation and spherical refractive errors in children. Am J Optom Physiol Optic. 1985;62(10):680-8.

22. Nathan J, Crewther $S$, Crewther D, Kiely P. Effects of retinal image degradation on ocular growth in cats. Invest Ophthalmol Vis Sci. 1984; 25(11):1300-6

23. Howlett MH, McFadden SA. Form-deprivation myopia in the guinea pig (Cavia porcellus). Vis Res. 2006;46(1-2):267-83.

24. Schaeffel F, Glasser A, Howland HC. Accommodation, refractive error and eye growth in chickens. Vis Res. 1988;28(5):639-57.

25. Wiesel TN, Raviola E. Myopia and eye enlargement after neonatal lid fusion in monkeys. 1977.

26. McBrien NA, Lawlor $\mathrm{P}$, Gentle A. Scleral remodeling during the development of and recovery from axial myopia in the tree shrew. Invest Ophthalmol Vis Sci. 2000:41(12):3713-9.

27. McBrien NA, Norton TT. Prevention of collagen crosslinking increases formdeprivation myopia in tree shrew. Exp Eye Res. 1994;59(4):475-86.

28. Wildsoet C, Wallman J. Choroidal and scleral mechanisms of compensation for spectacle lenses in chicks. Vis Res. 1995:35(9):1175-94.

29. Wallman J, Wildsoet C, Xu A, Gottlieb MD, Nickla DL, Marran L, et al. Moving the retina: choroidal modulation of refractive state. Vis Res. 1995;35(1):37-50

30. Liang H, Crewther DP, Crewther SG, Barila AM. A role for photoreceptor outer segments in the induction of deprivation myopia. Vis Res. 1995;35(9): 1217-25.

31. Beresford JA, Crewther SG, Kiely PM, Crewther DP. Comparison of refractive state and circumferential morphology of retina, choroid, and sclera in chick models of experimentally induced ametropia. Optom Vis Sci. 2001;78(1):40-9.

32. Jonas JB, Xu L, Wei WB, Pan Z, Yang H, Holbach L, et al. Retinal thickness and axial length. Invest Ophthalmol Vis Sci. 2016;57(4):1791-7.

33. Li XQ Larsen M, Munch IC. Subfoveal choroidal thickness in relation to sex and axial length in 93 danish university students. Invest Ophthalmol Vis Sci. 2011;52(11):8438-41.

34. Wei WB, Xu L, Jonas JB, Shao L, Du KF, Wang S, et al. Subfoveal choroidal thickness: the Beijing eye study. Ophthalmology. 2013;120(1):175-80.

35. Curtin BJ, Iwamoto T, Renaldo DP. Normal and staphylomatous sclera of high myopia. An electron microscopic study. Arch Ophthalmol. 1979;97(5):912-5.

36. Curtin BJ, Teng CC. Scleral changes in pathological myopia. Trans Am Acad Ophthalmol Otolaryngol. 1958;62(6):777-88. discussion 88-90

37. Fujikado T, Kawasaki Y, Suzuki A, Ohmi G, Tano Y. Retinal function with lensinduced myopia compared with form-deprivation myopia in chicks. Graefes Arch Clin Exp Ophthalmol. 1997;235(5):320-4.

38. Fujikado T, Hosohata J, Omoto T. Erg of form deprivation myopia and drug induced ametropia in chicks. Curr Eye Res. 1996:15(1):79-86.

39. Westbrook AM, Crewther DP, Crewther SG. Cone receptor sensitivity is altered in form deprivation myopia in the chicken. Optom Vis Sci. 1999; 76(5):326-38. 
40. Luu CD, Foulds WS, Tan DT. Features of the multifocal electroretinogram may predict the rate of myopia progression in children. Ophthalmology. 2007;114(8):1433-8.

41. Chen JC, Brown B, Schmid KL. Delayed mferg responses in myopia. Vis Res. 2006:46(8-9):1221-9.

42. Wildsoet CF, Pettigrew JD. Experimental myopia and anomalous eye growth-patterns unaffected by optic-nerve section in chickens - evidence for local-control of eye growth. Clin Vision Sci. 1988;3(2):99-107.

43. Schaeffel F, Troilo D, Wallman J, Howland HC. Developing eyes that lack accommodation grow to compensate for imposed defocus. Vis Neurosci. 1990;4(2):177-83.

44. Troilo D, Gottlieb MD, Wallman J. Visual deprivation causes myopia in chicks with optic nerve section. Curr Eye Res. 1987;6(8):993-9.

45. Wallman J, Gottlieb MD, Rajaram V, Fugate-Wentzek LA. Local retinal regions control local eye growth and myopia. Science. 1987;237(4810):73-7.

46. Wallman J, Winawer J. Homeostasis of eye growth and the question of myopia. Neuron. 2004:43(4):447-68.

47. Tkatchenko AV, Luo X, Tkatchenko TV, Vaz C, Tanavde VM, Maurer-Stroh S, et al. Large-scale microrna expression profiling identifies putative retinal mirna-mrna signaling pathways underlying form-deprivation myopia in mice. PLoS One. 2016:11(9):e0162541.

48. Tkatchenko AV, Walsh PA, Tkatchenko TV, Gustincich S, Raviola E. Form deprivation modulates retinal neurogenesis in primate experimental myopia. Proc Natl Acad Sci U S A. 2006;103(12):4681-6.

49. Brand C, Schaeffel F, Feldkaemper MP. A microarray analysis of retinal transcripts that are controlled by image contrast in mice. Mol Vis. 2007; 13(98-100):920-32.

50. McGlinn AM, Baldwin DA, Tobias JW, Budak MT, Khurana TS, Stone RA Form-deprivation myopia in chick induces limited changes in retinal gene expression. Invest Ophthalmol Vis Sci. 2007:48(8):3430-6.

51. Stone RA, McGlinn AM, Baldwin DA, Tobias JW, luvone PM, Khurana TS. Image defocus and altered retinal gene expression in chick: clues to the pathogenesis of ametropia. Invest Ophthalmol Vis Sci. 2011;52(8):5765-77.

52. Schippert R, Schaeffel F, Feldkaemper MP. Microarray analysis of retinal gene expression in egr-1 knockout mice. Mol Vis. 2009;15:2720.

53. Schippert R, Schaeffel F, Feldkaemper MP. Microarray analysis of retinal gene expression in chicks during imposed myopic defocus. Mol Vis. 2008;14:1589.

54. Rada JA, Wiechmann AF. Ocular expression of avian thymic hormone: changes during the recovery from induced myopia. Mol Vis. 2009;15:778-92.

55. Ashby RS, Feldkaemper MP. Gene expression within the amacrine cell layer of chicks after myopic and hyperopic defocus. Invest Ophthalmol Vis Sci. 2010;51(7):3726-35.

56. Riddell N, Crewther SG. Novel evidence for complement system activation in chick myopia and hyperopia models: a meta-analysis of transcriptome datasets. Sci Rep. 2017;7:9719.

57. Riddell N, Giummarra L, Hall N, Crewther S. Bidirectional expression of metabolic, structural, and immune pathways in early myopia and hyperopia. Front Neurosci. 2016;10(390)

58. Giummarra L, Crewther SG, Riddell N, Murphy MJ, Crewther DP. Pathway analysis identifies altered mitochondrial metabolism, neurotransmission, structural pathways and complement cascade in retina/rpe/ choroid in chick model of form-deprivation myopia. PeerJ. 2018;6:e5048.

59. Lam TC, Li KK, Lo SCL, Guggenheim JA, To CH. Application of fluorescence difference gel electrophoresis technology in searching for protein biomarkers in chick myopia. J Proteome Res. 2007:6(11):4135-49.

60. Jostrup R, Shen W, Burrows JTA, Sivak JG, McConkey BJ, Singer TD. Identification of myopia-related marker proteins in tilapia retinal, rpe, and choroidal tissue following induced form deprivation. Curr Eye Res. 2009; 34(11):966-75

61. Li SQ, Wu JS, Ding H, Liao AP, He H, Stell WK, et al. Flicker downregulates the content of crystallin proteins in form-deprived c57bl/6 mouse retina. Exp Eye Res. 2012;101:1-8.

62. Wu Y, Liu Q, To CH, Li KK, Chun RKM, Yu JFJ, et al. Differential retinal protein expressions during form deprivation myopia in albino Guinea pigs. Current Proteomics. 2014;11(1):37-47

63. Barathi VA, Chaurasia SS, Poidinger M, Koh SK, Tian D, Ho C, et al. Involvement of gaba transporters in atropine-treated myopic retina as revealed by itraq quantitative proteomics. J Proteome Res. 2014;13(11):4647-58.

64. Zhou YY, Chun RKM, Wang JC, Zuo B, Li KK, Lam TC, et al. Proteomic analysis of chick retina during early recovery from lens-induced myopia. Mol Med Report. 2018;18(1):59-66.
65. Bertrand E, Fritsch C, Diether S, Lambrou G, Mueller D, Schaeffel F, et al. Identification of apolipoprotein a-i as a "stop" signal for myopia. Mol Cell Proteomics. 2006;5(11):2158-66.

66. Riddell N, Faou P, Murphy M, Giummarra L, Downs RA, Rajapaksha H, et al. The retina/rpe proteome in chick myopia and hyperopia models: commonalities with inherited and age-related ocular pathologies. Mol Vis. 2017;23:872-88

67. Lam TC, Li KK, Lo SC, Guggenheim JA, To CH. A chick retinal proteome database and differential retinal protein expressions during early ocular development. J Proteome Res. 2006;5(4):771-84.

68. Finnegan S, Robson JL, Wylie M, Healy A, Stitt AW, Curry WJ. Protein expression profiling during chick retinal maturation: a proteomics-based approach. Proteome Sci. 2008:6:34.

69. Shan SW, DY-y T, Zuo B, To CH, Liu Q, SA MF, et al. Integrated swath-based and targeted-based proteomics provide insights into the retinal emmetropization process in guinea pig. J Proteomics. 2018;181:1-15.

70. Riddell N, Crewther SG. Integrated comparison of gwas, transcriptome, and proteomics studies highlights similarities in the biological basis of animal and human myopia. Invest Ophthalmol Vis Sci. 2017;58(1):660-9.

71. Magdeldin S, Enany S, Yoshida Y, Xu B, Zhang Y, Zureena Z, et al. Basics and recent advances of two dimensional- polyacrylamide gel electrophoresis. Clin Proteomics. 2014;11(1):16.

72. Shelton L, Troilo D, Lerner MR, Gusev Y, Brackett DJ, Rada JS. Microarray analysis of choroid/rpe gene expression in marmoset eyes undergoing changes in ocular growth and refraction. Mol Vis. 2008;14:1465-79.

73. Manoli T, Gretz N, Grone HJ, Kenzelmann M, Eils R, Brors B. Group testing for pathway analysis improves comparability of different microarray datasets. Bioinformatics. 2006:22(20):2500-6.

74. Subramanian A, Tamayo P, Mootha VK, Mukherjee S, Ebert BL, Gillette MA, et al. Gene set enrichment analysis: a knowledge-based approach for interpreting genome-wide expression profiles. Proc Natl Acad Sci U S A. 2005;102(43):15545-50.

75. Hendriks M, Verhoeven VJ, Buitendijk GH, Polling JR, Meester-Smoor MA, Hofman A, et al. Development of refractive errors-what can we learn from inherited retinal dystrophies? Am J Ophthalmol. 2017;182:81-9.

76. Tedja MS, Wojciechowski R, Hysi PG, Eriksson N, Furlotte NA, Verhoeven VJM, et al. Genome-wide association meta-analysis highlights light-induced signaling as a driver for refractive error. Nat Genet. 2018;50(6):834-48.

77. Crewther DP. The role of photoreceptors in the control of refractive state. Prog Retin Eye Res. 2000;19(4):421-57.

78. Mey J, Thanos S. Development of the visual system of the chick. I Cell differentiation and histogenesis Brain Res Brain Res Rev. 2000;32(2-3):343-79.

79. Bhuin T, Roy JK. Rab proteins: the key regulators of intracellular vesicle transport. Exp Cell Res. 2014;328(1):1-19.

80. Su X, Lodhi IJ, Saltiel AR, StahI PD. Insulin-stimulated interaction between insulin receptor substrate 1 and p85alpha and activation of protein kinase b/akt require rab5. J Biol Chem. 2006:281(38):27982-90.

81. He A, Liu X, Liu L, Chang Y, Fang F. How many signals impinge on glut4 activation by insulin? Cell Signal. 2007;19(1):1-7.

82. Clausen MV, Hilbers F, Poulsen $\mathrm{H}$. The structure and function of the na,katpase isoforms in health and disease. Front Physiol. 2017:8:371.

83. Doncheva NT, Assenov Y, Domingues FS, Albrecht M. Topological analysis and interactive visualization of biological networks and protein structures. Nat Protoc. 2012;7(4):670.

84. Fischer AJ, Reh TA. Identification of a proliferating marginal zone of retinal progenitors in postnatal chickens. Dev Biol. 2000;220(2):197-210.

85. Marzluff WF, Duronio RJ. Histone mrna expression: multiple levels of cell cycle regulation and important developmental consequences. Curr Opin Cell Biol. 2002;14(6):692-9.

86. Zhao X, McKillop-Smith S, Muller B. The human histone gene expression regulator $\mathrm{hbp} / \mathrm{slbp}$ is required for histone and DNA synthesis, cell cycle progression and cell proliferation in mitotic cells. J Cell Sci. 2004;117(Pt 25): 6043-51.

87. Tumaneng K, Russell RC, Guan KL. Organ size control by hippo and tor pathways. Curr Biol. 2012;22(9):R368-79.

88. Thomas $\mathrm{G}$. An encore for ribosome biogenesis in the control of cell proliferation. Nat Cell Biol. 2000;2(5):E71-2.

89. Zeng L, Wan Y, Li D, Wu J, Shao M, Chen J, et al. The $m$ subunit of murine translation initiation factor eif3 maintains the integrity of the eif3 complex and is required for embryonic development, homeostasis, and organ size control. J Biol Chem. 2013;288(42):30087-93. 
90. Akerfelt M, Morimoto RI, Sistonen L. Heat shock factors: integrators of cell stress, development and lifespan. Nat Rev Mol Cell Biol. 2010;11(8):545-55.

91. Raices M, D'Angelo MA. Nuclear pore complex composition: a new regulator of tissue-specific and developmental functions. Nat Rev Mol Cell Biol. 2012;13(11):687-99.

92. Capelson M, Hetzer MW. The role of nuclear pores in gene regulation, development and disease. EMBO Rep. 2009;10(7):697-705.

93. Kressler D, Bange G, Ogawa Y, Stjepanovic G, Bradatsch B, Pratte D, et al. Synchronizing nuclear import of ribosomal proteins with ribosome assembly. Science. 2012;338(6107):666-71.

94. Shalgi R, Hurt JA, Krykbaeva I, Taipale M, Lindquist S, Burge CB. Widespread regulation of translation by elongation pausing in heat shock. Mol Cell. 2013;49(3):439-52.

95. Wild T, Horvath P, Wyler E, Widmann B, Badertscher L, Zemp I, et al. A protein inventory of human ribosome biogenesis reveals an essential function of exportin 5 in 60s subunit export. PLoS Biol. 2010;8(10):e1000522.

96. Toth $A B$, Shum AK, Prakriya M. Regulation of neurogenesis by calcium signaling. Cell Calcium. 2016;59(2-3):124-34.

97. Agostini M, Romeo F, Inoue S, Niklison-Chirou MV, Elia AJ, Dinsdale D, et al. Metabolic reprogramming during neuronal differentiation. Cell Death Differ. 2016;23(9):1502-14.

98. Shah BH, Hausman RE. Effect of insulin on gabaergic development in the embryonic chick retina. Brain Res Dev Brain Res. 1993;72(2):151-8.

99. Ben-Ari Y. Excitatory actions of gaba during development: the nature of the nurture. Nat Rev Neurosci. 2002;3(9):728-39.

100. Murray Jl, Whitfield ML, Trinklein ND, Myers RM, Brown PO, Botstein D Diverse and specific gene expression responses to stresses in cultured human cells. Mol Biol Cell. 2004;15(5):2361-74.

101. Grummt I. The nucleolus-guardian of cellular homeostasis and genome integrity. Chromosoma. 2013;122(6):487-97.

102. Kultz D. Evolution of the cellular stress proteome: from monophyletic origin to ubiquitous function. J Exp Biol. 2003;206(Pt 18):3119-24.

103. Ring H, Boije H, Daniel C, Ohlson J, Ohman M, Hallbook F. Increased a-to-i rna editing of the transcript for Gabaa receptor subunit alpha3 during chick retinal development. Vis Neurosci. 2010;27(5-6):149-57.

104. Goto H, Terunuma M, Kanematsu T, Misumi Y, Moss SJ, Hirata M. Direct interaction of n-ethylmaleimide-sensitive factor with gaba(a) receptor beta subunits. Mol Cell Neurosci. 2005;30(2):197-206.

105. Stone RA, Liu J, Sugimoto R, Capehart C, Zhu X, Pendrak K. Gaba, experimental myopia, and ocular growth in chick. Invest Ophthalmol Vis Sci. 2003;44(9):3933-46.

106. Yang J, Reinach PS, Zhang S, Pan M, Sun W, Liu B, et al. Changes in retinal metabolic profiles associated with form deprivation myopia development in Guinea pigs. Sci Rep. 2017;7(1):2777.

107. Sha F, Ye X, Zhao W, Xu CL, Wang L, Ding MH, et al. Effects of electroacupuncture on the levels of retinal gamma-aminobutyric acid and its receptors in a Guinea pig model of lens-induced myopia. Neuroscience. 2015;287:164-74

108. Guoping L, Xiang Y, Jianfeng W, Dadong G, Jie H, Wenjun J, et al. Alterations of glutamate and gamma-aminobutyric acid expressions in normal and myopic eye development in Guinea pigs. Invest Ophthalmol Vis Sci. 2017;58(2):1256-65.

109. Chebib M, Hinton T, Schmid KL, Brinkworth D, Qian H, Matos S, et al. Novel, potent, and selective gabac antagonists inhibit myopia development and facilitate learning and memory. J Pharmacol Exp Ther. 2009:328(2):448-57.

110. Cheng ZY, Wang XP, Schmid KL, Han YF, Han XG, Tang HW, et al. Gabab receptor antagonist cgp46381 inhibits form-deprivation myopia development in Guinea pigs. Biomed Res Int. 2015;2015:207312.

111. Schmid KL, Strasberg G, Rayner CL, Hartfield PJ. The effects and interactions of gabaergic and dopaminergic agents in the prevention of form deprivation myopia by brief periods of normal vision. Exp Eye Res. 2013;1 10:88-95.

112. Turrigiano GG. The self-tuning neuron: synaptic scaling of excitatory synapses. Cell. 2008;135(3):422-35

113. Lalioti VS, Ilari A, O'Connell DJ, Poser E, Sandoval IV, Colotti G. Sorcin links calcium signaling to vesicle trafficking, regulates polo-like kinase 1 and is necessary for mitosis. PLoS One. 2014;9(1):e85438.

114. Treves S, Franzini-Armstrong C, Moccagatta L, Arnoult C, Grasso C, Schrum A, et al. Junctate is a key element in calcium entry induced by activation of insp3 receptors and/or calcium store depletion. J Cell Biol. 2004;166(4):537-48.

115. Lisman J, Yasuda R, Raghavachari S. Mechanisms of camkii action in longterm potentiation. Nat Rev Neurosci. 2012;13(3):169.
116. Yamauchi T. Neuronal ca2+/calmodulin-dependent protein kinase ii-discovery, progress in a quarter of a century, and perspective: implication for learning and memory. Biol Pharm Bull. 2005;28(8):1342-54.

117. Rose EM, Koo JC, Antflick JE, Ahmed SM, Angers S, Hampson DR. Glutamate transporter coupling to na,k-atpase. J Neurosci. 2009;29(25):8143-55.

118. Kirischuk S, Heja L, Kardos J, Billups B. Astrocyte sodium signaling and the regulation of neurotransmission. Glia. 2016;64(10):1655-66.

119. Murphy MJ, Crewther SG. Ouabain inhibition of na/k-atpase across the retina prevents signed refractive compensation to lens-induced defocus, but not default ocular growth in young chicks. F1000Res. 2013;2:97.

120. Yu F, Lam T, Liu L. Chun RK-m, Cheung JK-w, li K et al. isotope-coded protein label based quantitative proteomic analysis reveals significant upregulation of apolipoprotein a1 and ovotransferrin in the myopic chick vitreous. Sci Rep. 2017;7(1):12649.

121. Rauen T, Rothstein JD, Wassle H. Differential expression of three glutamate transporter subtypes in the rat retina. Cell Tissue Res. 1996;286(3):325-36.

122. Pow DV. Amino acids and their transporters in the retina. Neurochem Int 2001;38(6):463-84

123. Pignataro L, Sitaramayya A, Finnemann SC, Sarthy VP. Nonsynaptic localization of the excitatory amino acid transporter 4 in photoreceptors. Mol Cell Neurosci. 2005:28(3):440-51.

124. Hilgen G, Huebner AK, Tanimoto N, Sothilingam V, Seide C, Garcia Garrido $\mathrm{M}$, et al. Lack of the sodium-driven chloride bicarbonate exchanger ncbe impairs visual function in the mouse retina. PLoS One. 2012;7(10):e46155.

125. Vardi N, Zhang L-L, Payne JA, Sterling P. Evidence that different cation chloride cotransporters in retinal neurons allow opposite responses to gaba. J Neurosci. 2000;20(20):7657-63.

126. Suzuki M, Seki G, Yamada H, Horita S, Fujita T. Functional roles of electrogenic sodium bicarbonate cotransporter nbce1 in ocular tissues. Open Ophthalmol J. 2012;6:36-41.

127. Smith EL, Fox DA, Duncan GC. Refractive-error changes in kitten eyes produced by chronic on-channel blockade. Vis Res. 1991;31(5):833-44.

128. Crewther D, Crewther S, Xie R. Changes in eye growth produced by drugs which affect retinal on or off responses to light. J Ocul Pharmacol Ther. 1996;12(2):193-208.

129. Crewther D, Crewther S. Pharmacological modification of eye growth in normally reared and visually deprived chicks. Curr Eye Res. 1990;9(8):733-40.

130. Crewther S, Crewther DP. Inhibition of retinal on/off systems differentially affects refractive compensation to defocus. Neuroreport. 2003;14(9):1233-7.

131. Pardue MT, Faulkner AE, Fernandes A, Yin $H$, Schaeffel F, Williams RW, et al. High susceptibility to experimental myopia in a mouse model with a retinal on pathway defect. Invest Ophthalmol Vis Sci. 2008;49(2):706-12.

132. Chakraborty R, Park HN, Hanif AM, Sidhu CS, luvone PM, Pardue MT. On pathway mutations increase susceptibility to form-deprivation myopia. Exp Eye Res. 2015;137:79-83.

133. Chakraborty R, Park H, Aung MH, Tan CC, Sidhu CS, luvone PM, et al. Comparison of refractive development and retinal dopamine in off pathway mutant and c57bl/6j wild-type mice. Mol Vis. 2014;20:1318-27.

134. Liang $H$, Crewther SG, Crewther DP, Junghans BM. Structural and elemental evidence for edema in the retina, retinal pigment epithelium, and choroid during recovery from experimentally induced myopia. Invest Ophthalmol Vis Sci. 2004;45(8):2463-74.

135. Crewther SG, Liang $H$, Junghans BM, Crewther DP. Ionic control of ocular growth and refractive change. Proc Natl Acad Sci. 2006;103(42):15663-8.

136. Jin N, Stjernschantz J. Regional blood flow in the myopic chick eye during and after form deprivation: a study with radioactively-labelled microspheres. Exp Eye Res. 2000;71(3):233-8.

137. Shih Y-F, Fitzgerald ME, Norton TT, Gamlin PD, Hodos W, Reiner A. Reduction in choroidal blood flow occurs in chicks wearing goggles that induce eye growth toward myopia. Curr Eye Res. 1993;12(3):219-27.

138. Frost MR, Norton TT. Alterations in protein expression in tree shrew sclera during development of lens-induced myopia and recovery. Invest Ophthalmol Vis Sci. 2012;53(1):322-36.

139. He L, Frost MR, Siegwart JT Jr, Norton TT. Gene expression signatures in tree shrew choroid during lens-induced myopia and recovery. Exp Eye Res. 2014 123:56-71.

140. Rogers $L$. Light input and the reversal of functional lateralization in the chicken brain. Behav Brain Res. 1990;38(3):211-21.

141. Rogers LJ, Sink HS. Transient asymmetry in the projections of the rostral thalamus to the visual hyperstriatum of the chicken, and reversal of its direction by light exposure. Exp Brain Res. 1988;70(2):378-84. 
142. Rogers $\sqcup$, Bolden SW. Light-dependent development and asymmetry of visual projections. Neurosci Lett. 1991;121(1-2):63-7.

143. Rappsilber J, Ishihama Y, Mann M. Stop and go extraction tips for matrixassisted laser desorption/ionization, nanoelectrospray, and lc/ms sample pretreatment in proteomics. Anal Chem. 2003;75(3):663-70.

144. Cox J, Mann M. Maxquant enables high peptide identification rates, individualized p.P.B.-range mass accuracies and proteome-wide protein quantification. Nat Biotechnol. 2008;26(12):1367-72.

145. Cox J, Hein MY, Luber CA, Paron I, Nagaraj N, Mann M. Accurate proteomewide label-free quantification by delayed normalization and maximal peptide ratio extraction, termed maxlfa. Mol Cell Proteomics. 2014;13(9):2513-26.

146. Lazar C. Imputelcmd: a collection of methods for left-censored missing data imputation. In, R package, version 2 edn. 2015;

147. Ritchie ME, Phipson B, Wu D, Hu Y, Law CW, Shi W, et al. Limma powers differential expression analyses for ma-sequencing and microarray studies. Nucleic Acids Res. 2015;43(7):e47.

148. Sonnhammer EL, Ostlund G. Inparanoid 8: Orthology analysis between 273 proteomes, mostly eukaryotic. Nucleic Acids Res. 2015;43(Database issue): D234-9.

149. Croft D, O'Kelly G, Wu G, Haw R, Gillespie M, Matthews L, et al. Reactome: a database of reactions, pathways and biological processes. Nucleic Acids Res. 2011:39(Database):D691-7.

150. Merico D, Isserlin R, Stueker O, Emili A, Bader GD. Enrichment map: a network-based method for gene-set enrichment visualization and interpretation. PLoS One. 2010;5(11):e13984.

151. Subramanian A, Kuehn H, Gould J, Tamayo P, Mesirov JP. Gsea-p: a desktop application for gene set enrichment analysis. Bioinformatics. 2007;23(23): 3251-3.

152. Spinelli L, Carpentier S, Montanana Sanchis F, Dalod M, Vu Manh TP. Bubblegum: automatic extraction of phenotype molecular signatures and comprehensive visualization of multiple gene set enrichment analyses. BMC Genomics. 2015;16:814.

153. D'haeseleer P. How does gene expression clustering work? Nat Biotechnol. 2005;23(12):1499-501.

154. The broad institute morpheus web app [https://software.broadinstitute.org/ morpheus/].

155. Wu J, Vallenius T, Ovaska K, Westermarck J, Mäkelä TP, Hautaniemi S. Integrated network analysis platform for protein-protein interactions. Nat Methods. 2009:6(1):75-7.

156. Assenov Y, Ramirez F, Schelhorn SE, Lengauer T, Albrecht M. Computing topological parameters of biological networks. Bioinformatics. 2008;24(2):282-4.

Ready to submit your research? Choose BMC and benefit from:

- fast, convenient online submission

- thorough peer review by experienced researchers in your field

- rapid publication on acceptance

- support for research data, including large and complex data types

- gold Open Access which fosters wider collaboration and increased citations

- maximum visibility for your research: over $100 \mathrm{M}$ website views per year

At BMC, research is always in progress.

Learn more biomedcentral.com/submissions 